\title{
A Radical-Triggered Reaction Mechanism of the Green-To-Red Photoconversion of EosFP
}

Clyde Fare ${ }^{1,2}$, Letong Yuan ${ }^{\Gamma 1}$, Violeta Cordon-Preciado ${ }^{1}$, Jasper J. Michels ${ }^{3}$, Michael J. Bearpark ${ }^{2}$, Peter Rich ${ }^{4}$ and Jasper J. van Thor ${ }^{*}$.

1 Imperial College London, Molecular Biophysics, South Kensington Campus. SW7 2AZ, London, UK

2 Imperial College London, Department of Chemistry, Molecular Sciences Research Hub, Imperial College London, White City Campus, 80 Wood Lane, London, UK

3 Max Planck Institute for Polymer Research, Division of Molecular Electronics, Ackermannweg 10, 55128 Mainz, Germany

4 University College London, Department of Structural and Molecular Biology, Gower Street, London WC1E 6BT, UK

* Corresponding author. E-mail: j.vanthor@imperial.ac.uk. Phone +44-20-75945071

Г Deceased 28 March 2018

Abstract 
Reaction intermediates in the green-to-red photoconversion of the photochromic fluorescent protein EosFP have been observed using high-intensity continuous blue illumination. An intermediate was identified through light induced accumulation that continues to convert the green form in subsequent darkness, putatively containing a tyrosyl radical, albeit with anomalously shifted features in both electronic and FTIR spectra. Lowering the $\mathrm{pH}$ to 5.5 significantly delays the decay of this tyrosyl intermediate, which is accompanied by Stark-shifted features in the electronic spectra of reactants and products. Vibrational mode assignments for the high frequency and fingerprint FTIR spectral regions of reaction intermediates support a proposed sequence of events where the newly formed $\mathrm{C} \alpha=\mathrm{C} \beta$ ethylenic bond precedes modifications on the His62 imidazole ring and confirms a $\mathrm{C}=\mathrm{O}\left(\mathrm{NH}_{2}\right)$ product group on Phe61. We propose a reaction mechanism that involves tyrosyl generation via singlet excited state mediated oxidation which subsequently triggers the covalent reactions by oxidation of the green chromophore.

\section{Introduction}

EosFP is a green-to-red photoconverting fluorescent protein from the stony coral Lobophyllia hemprichii that was first discovered and characterised by Wiedenmann ${ }^{1}$. It emits strong green fluorescence at $516 \mathrm{~nm}$ which upon near-UV irradiation photoconverts to emit red fluorescence at $581 \mathrm{~nm}$. Like the previously reported green-to-red photoconverting fluorescent protein Kaede ${ }^{2}$ the chromophore derives from the tripeptide His-Tyr-Gly and like GFP it contains a 4-(phydroxy-benzylidene)-5-imidazolinone subunit (Fig. 1). 
The mechanism of photoconversion for this class of fluorescent proteins was initially proposed by Mizuno et al. ${ }^{3}$, on the basis of mass spectrometry and NMR of the green and red forms of Kaede. They suggested a model involving a light induced $\beta$-elimination reaction leading to cleavage of the His $N_{\alpha}-C_{\alpha}$ bond. This would then lead to extension of the conjugated $\pi$ electron system to incorporate the imidazole side chain of the histidine into the chromophore and hence downshifting of the fluorescent wavelength. While this outline has been broadly accepted the details of the mechanism are subject to considerable debate. Mizuno et $\mathrm{al}^{3}$ suggested that the imidazole of His-62 would become doubly protonated prior to $\beta$-elimination. Nienhaus ${ }^{4}$ proposed an E2 mechanism whereby Glu 212 acted as a base that abstracts a proton from His-62 $C_{\beta}$. They also proposed that photoconversion involves an initial excited state proton transfer (ESPT) from Tyr 63 to the $N_{\square}$ of the His 62 imidazole group arguing that the absence or reduced photoconversion of the anionic species suggests involvement of the Tyr 63 proton. This proton transfer was proposed to in turn setup the imidazole $N_{\square}-H$ to donate its proton to the Phe-61 carbonyl setting up the elimination reaction. In their subsequent paper ${ }^{5}$ they showed that an EosFP mutant E212Q no longer photoconverts supporting their suggestion that glutamate is acting as a proton acceptor during photoconversion. By contrast Mizuno et al ${ }^{3}$ proposed a water assisted mechanism to account for the loss of the water molecule close the Tyr 63 when moving from the green to red form. In their picture rather than abstracting a proton Glu 212 stabilises the transition state for the elimination reaction. All authors agree on the significance of the His 62 residue and that the neutral p-hydroxybenzylidene chromophore is the gateway species to photoconversion.

In contrast to Neinhaus, Tsutsui et al ${ }^{6}$ proposed an E1 reaction mechanism on the basis of observations of the closely related KikGR protein. The difference between the chromophores is 
the presence of a water molecule close to His 62 in EosFP but not in KikGRX. KikGR also photoconverts but, in contrast to EosFP, the red chromophore forms in its cis form which requires rotation about the $C_{\alpha}-C_{\beta}$ bond, this implies the presence of a carbocation and hence an E1 mechanism.

Lelimousin et al ${ }^{7}$ performed QM/MM calculations, applying OPLS-AA to the MM region and PDDG-PM3 to the QM region. Their calculations supported an E1 based photoconversion suggesting it proceeds via an intersystem crossing from the initial singlet excited state through a triplet state to the ground state. They dispute the E2 mechanism involving a proton transfer from Tyr 63 on the grounds that no hydrogen bonding network can be found that links Tyr 63 to His 62. Further they point out that the $N_{\epsilon}$ of His 62 suggested to be a site of protonation in the ESPT model is in a non-polar environment and their calculations assign a high energetic cost to the proposed final $\mathrm{H}$ transfer between the $N_{\epsilon}$ to the $N_{\sigma}$ of $75 \mathrm{~kJ} / \mathrm{mol}$ and an even higher energetic barrier of $150 \mathrm{~kJ} / \mathrm{mol}$ for the cleavage step. The inability of the anion to photoconvert is attributed to the presence of a large activation barrier for proton transfer from $N_{\sigma}$ of $\mathrm{His}_{62}$ in the initial step of their reaction mechanism. Li et al ${ }^{8}$ performed ONIOM calculations on the FP 'Kaede' with B3LYP and SAC-CI used as high levels of theory and AMBER used for the low level of theory. They computed transition states and reaction pathways for the proposed E1/E2 mechanisms as well an investigating an additional E1cb mechanism. They concluded on energetic grounds that E1 and E1cb were most likely to compete during photoconversion and that the E2 pathway was much higher in energy. Kim et al ${ }^{9}$ constructed a least evolved ancestor for red-to-green photoactivatable proteins, from which they proposed key residues within the protein required for photoconversion. They also hypothesise a new mechanism based on light induced chromophore twisting leading to disruption of charge-charge interactions between the 
chromophore and surrounding residues to enhance the basicity of Glu 212 leading to proton abstraction of the His-62 proton. In further work they argue for the E2 mechanism ${ }^{10}$ on the basis of the energetic cost of forming a carbanion.

Most discussions regarding the E1 and E2 type mechanisms of green-to-red conversion include the assumption of requiring blue excitation of the protonated chromophore. However, three distinct photoreactions following anion chromophore excitation have been reported that question this assumption. Using very intense illumination of mEos2, Thedie et al ${ }^{11}$ observed the population of a long-lived non-fluorescent state, which could be readily re-converted using weak blue illumination. The photoconversion was however characterised by fluorescence and no absorption differences were shown. Second, Makarov et al ${ }^{12}$ showed that in Dendra2 green-tored absorption is seen with direct illumination of the anion chromophore at $488 \mathrm{~nm}$, albeit with reduced quantum efficiency. Their careful analysis excluded direct excitation in the tail of the neutral chromophore absorption at $488 \mathrm{~nm}$ from kinetics arguments. The quantum efficiency was thus reported to be $6.3 \times 10^{-5}$ at $488 \mathrm{~nm}$ compared to $1.5 \times 10^{-3}$ for $400 \mathrm{~nm}$ illumination ${ }^{12}$. The reduced quantum efficiency for photoconversion of the anion relative to the neutral chromophore is reminiscent of the documented electron transfer based photoconversion of the Green Fluorescent Protein ${ }^{13}$. Third, a two-colour observation of green-to-red conversion in Dendra2 also involves the anion chromophore ${ }^{14-15}$. Illumination with $488 \mathrm{~nm}$ was shown to populate a 'primed' intermediate that can subsequently support efficient green-to-red conversion using red wavelengths from $700 \mathrm{~nm}-800 \mathrm{~nm}$. An important observation was the apparent 10ms lifetime of the 'primed' intermediate, obtained from sequential illumination measurements ${ }^{15}$. 


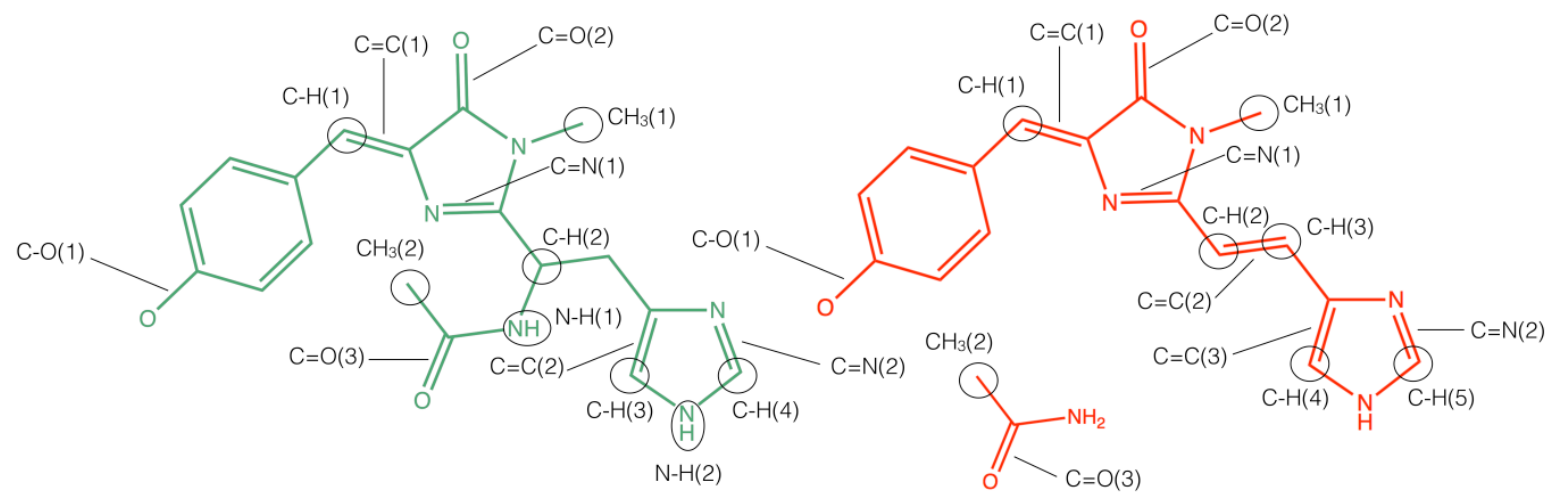

Figure 1. Covalent structures of the Green (Left) and Red (Right) chromophores of EosFP in anion form. Bond labels are indicated with reference to tabulated results from harmonic frequency calculations (SI Tables s1,s2).

There is currently no consensus in the literature for the details of the mechanism of green-tored conversion, particularly regarding the light driven process that triggers conversion. Here, we show that illumination of the neutral ground state generates an intermediate that includes the recovery of the ground state chromophore, which is competent to subsequently complete the green-to-red transition in EosFP. The spectral characterization supports a novel radical based mechanism involving a nearby tyrosyl.

\section{Methods}

Protein Expression and Purification

EosFP was expressed in E.coli BL21 cells containing a 6xHis-tagged version of EosFP as described previously ${ }^{1}$. The protein was purified using Ni-NTA affinity resin (Thermo Scientific) 
and eluted samples were dialysed in 5mM TRIS-Cl pH7.8 50mM NaCl. Samples were concentrated using Vivaspin 20 centricons (Sartorius) and exchanged to a citric phosphate buffer was prepared in ${ }^{1} \mathrm{H}_{2} \mathrm{O}$ and ${ }^{2} \mathrm{H}_{2} \mathrm{O}$ to generate four sets of samples at $\mathrm{p}^{1} \mathrm{H}$ 5.1, $\mathrm{p}^{1} \mathrm{H}$ 6.9, $\mathrm{p}^{2} \mathrm{H} 5.1$ and $\mathrm{p}^{2} \mathrm{H}$ 6.9.

Spectroscopy

UV-VIS absorption spectroscopy and kinetics were recorded on an Agilent 8453 UV-VIS spectrophotometer at room temperature. Illumination conditions for UV-VIS kinetics were 100 $\mathrm{mW} / \mathrm{cm}^{2}$ at $405 \mathrm{~nm}$ and spectra were recorded every 5 seconds. Spectral kinetics occurring during continuous wave (cw) illumination are presented with reference to 'Phase 1' with indication of the rate constants using ' $\mathrm{k} 1$ ', while subsequent kinetics measured in darkness are referred to as 'Phase 2' with indication of the rate constants using ' $k 2$ ', in both UV-VIS and FTIR spectroscopy. FTIR spectra were measured at room temperature and $4 \mathrm{~cm}^{-1}$ resolution with a Bruker ISF 66/S spectrometer fitted with a liquid nitrogen-cooled MCT-A detector. Illumination conditions for FTIR kinetics were $~ 10-20 \mathrm{~mW} / \mathrm{cm}^{2}$ at $405 \mathrm{~nm}$ and spectra were recorded every 20 seconds. Data were globally fitted to homogeneous, sequential, models using Tikhonov regularization using a python implementation based on lmfit 'The Ultrafast Toolbox v2. Available at https://github.com/Clyde-fare/ultrafast tb.' The resulting difference spectra are generated from coupled differential equations as evolution associated difference spectra (EADS) ${ }^{16}$. This code implementation was based on the Ultrafast Toolbox previously described ${ }^{16}$ and the python based PyLDM package ${ }^{17}$.

\section{Results}


Transient UV-VIS and FTIR studies at $p^{1} H / p^{2} H 6.9$ with the anion-dominated chromophore

Time-resolved UV-VIS and FTIR measurements were conducted under conditions of intense illumination (Methods) and selection of a ${ }^{1} \mathrm{H}$ and $\mathrm{p}^{2} \mathrm{H}$ of 6.9 which is sufficiently above the pKa values of $\sim 5.5$ of both the green and the red chromophore to study the chromophore anion spectra selectively ${ }^{1}$. The high intensity of $\mathrm{cw}$ blue illumination at $405 \mathrm{~nm}$ allowed accumulation of intermediates under conditions of a low primary quantum yield, such that subsequent thermal conversion could be separated by kinetic analysis. The global fitting separates spectroscopic differences which are presented as sequential reactions. Figure 2 shows the globally fitted difference spectra in the 250-600 nm spectral window for a period of illumination ('Phase 1'; Fig 2A) and the subsequent period of darkness ('Phase 2'; Fig 2B). In the first reaction $\mathrm{k} 1(1)=1.0 \mathrm{~s}^{-1}$ of Phase 1, the major bleach at $506 \mathrm{~nm}$ indicates the depopulation of the green anion chromophore ('GA'), while the minor bleach at $373 \mathrm{~nm}$ indicates the depopulation of the minor protonated, neutral green chromophore ('GN'). The induced absorption at $437 \mathrm{~nm}$ is assigned to the red neutral chromophore ('RN') but can include product absorption of a reaction intermediate more clearly seen at lower $\mathrm{pH}$ as shown below (section 2). The $568 \mathrm{~nm}$ maximum is assigned to the red anion chromophore ('RA'), and the $325 \mathrm{~nm}$ maximum has S2 type contributions from both the RA and RN, which in the first reaction $\mathrm{k} 1(1)$ is dominated by the RN, as judged from equivalent low $\mathrm{pH}$ measurements (section 2). The spectrum of the second reaction $\mathrm{k} 1(2)=0.015 \mathrm{~s}^{-}$ ${ }^{1}$ is notably different from the first reaction $\mathrm{k} 1(1)$. While the major bleach at $506 \mathrm{~nm}$ of GA is present, the induced absorption at $\sim 436 \mathrm{~nm}$ is decreased in intensity relative to $\mathrm{k} 1(1)$, a feature that was reproducibly resolved. Notably, the RA species is developed much stronger in reaction 
k1(2), with a reproducibly observed minor red-shift of its maximum at $571 \mathrm{~nm}$ and a pronounced vibronic sideband at $534 \mathrm{~nm}$ corresponding to a $1213 \mathrm{~cm}^{-1}$ Franck-Condon active mode. A vibronic sideband at $\sim 475 \mathrm{~nm}$ is present in the GA bleach in k1(1) and k1(2) as well (Figure 2A). The S2 feature is accordingly shifted to $336 \mathrm{~nm}$, with more prominent RA contribution compared to $\mathrm{k} 1(1)$. The RA product of $\mathrm{k} 1(1)$ is thus identified from the blue-shifted maximum, and weak intensity as a precursor to the RA product of $k(1) 2$. The reduced intensities of RN and RA contributions in $\mathrm{k}(1) 1$ relative to $\mathrm{k}(1) 2$ indicate that the slower second reaction includes thermal deprotonation of $\mathrm{RN}$ with an intrinsic rate corresponding to $\mathrm{k}(1) 2$. The $\mathrm{k}(1) 2$ reaction thus further converts the RN species and modifies the RA spectrum (Scheme 1).

Scheme 1

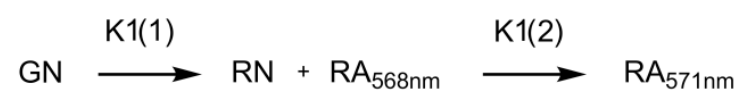

In contrast to the deprotonation rate of RN, the thermal protonation of GA should be faster than the first reaction $\mathrm{k} 1(1)=1.0 \mathrm{~s}^{-1}$, from the observation of strong GA bleaching in $\mathrm{k}(1) 1$ with cw illumination of minor GN population. Since the GN and GA bleaching are kinetically linked, as determined from the global analysis, the rate of protonation of RA should exceed the phototransformation if this is selective for the GN state. An alternative possibility is that in the first reaction $\mathrm{k}(1) 1$ a reactive intermediate 'I' is generated with re-formation of the GN ground state and redox-modification of the chromophore environment (Scheme 2). A charged intermediate could subsequently be competent in transforming either the GN or the GA state.

Scheme 2 


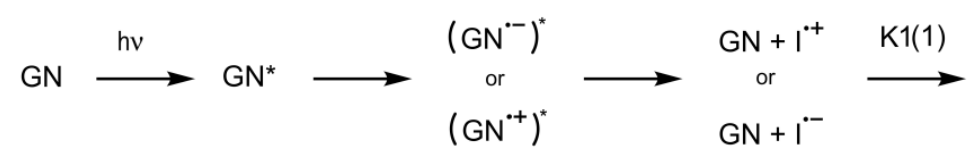

Subsequent to $405 \mathrm{~nm}$ illumination, the sample continued to convert thermally in darkness (Phase 2, Fig 2B). While two components were necessary for the global fit of difference spectra that developed following the preceding illumination period, both were similar in appearance to that associated with the second reaction $\mathrm{k} 1(2)$ of Phase 1 . As the rates $\mathrm{k} 1(2)$ and $\mathrm{k} 2(2)$ correspond in magnitude, it is likely that $\mathrm{k} 1(2)$ also includes significant thermally driven, rather than direct light-induced, character. In addition to the kinetic correspondence, the associated spectra are also similar, which further supports the significant thermal contribution assigned to k1(2). The dark reactions, reported here for the first time, are thus indicative that reactive intermediates accumulate under our experimental conditions of cw illumination. It is noted that the dark reactions show the same ground state bleach spectral features as those under illumination. The spectra are dominated by GA -> RA features for both k2(1) and k2(2), although the UV-blue region indicates the occurance of scattering that may prevent accurate determination of GN and RN contributions (Fig. 2). The RA and GA contributions in k2(2) correspond to those in $\mathrm{k} 1$ (2) but have $~ 10 \%$ of their amplitude (Figure 2). Measurements made in ${ }^{2} \mathrm{H}_{2} \mathrm{O}$ were not significantly different with $\mathrm{k} 1(1)=1.0 \mathrm{~s}^{-1}$, and $\mathrm{k} 1(2)=0.021 \mathrm{~s}^{-1}, \mathrm{k} 2(1)=0.041 \mathrm{~s}^{-1}$ and $\mathrm{k} 2(2)=0.027 \mathrm{~s}^{-}$ ${ }^{1}$ and similar spectral features (SI: Fig S1). 

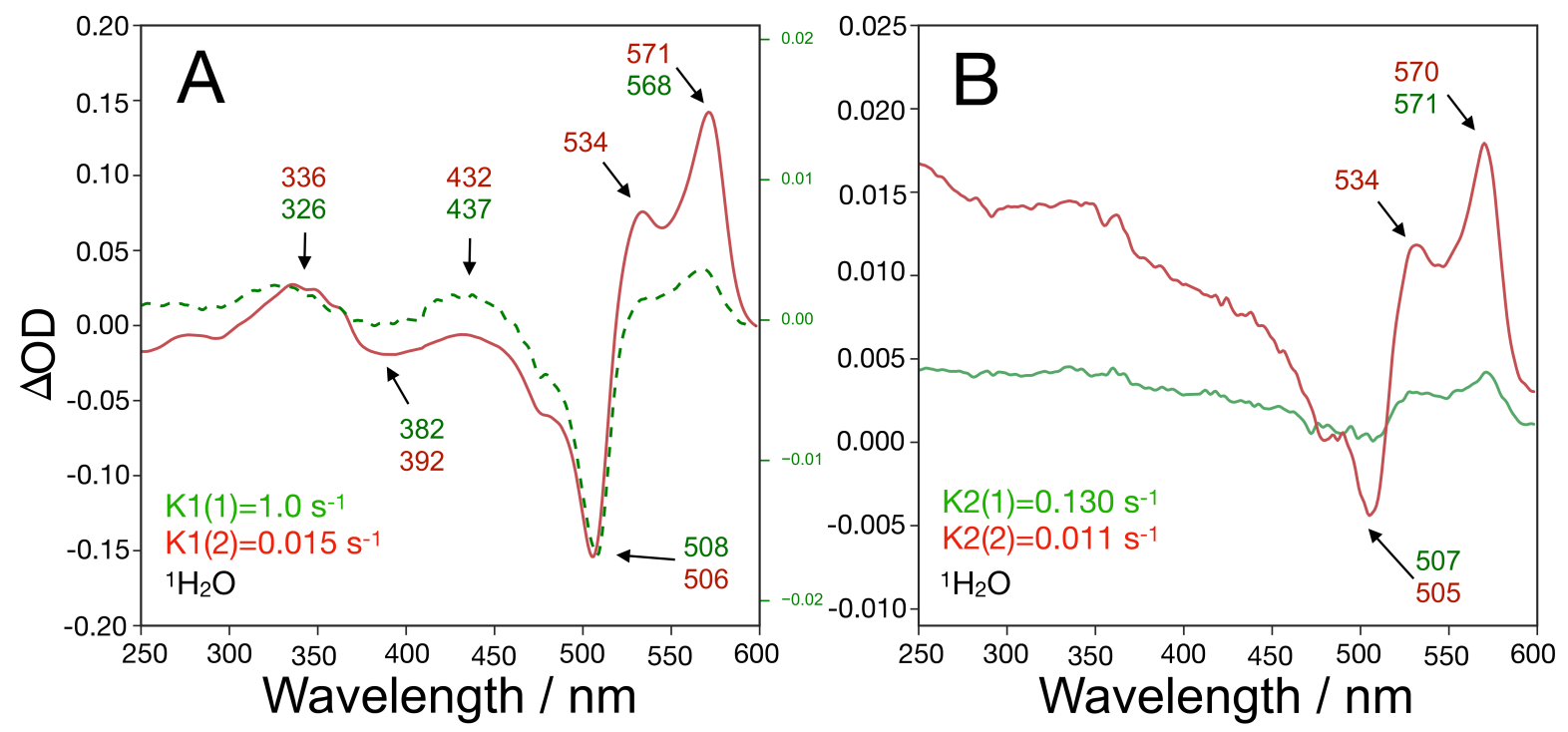

Figure 2. Globally fitted time resolved UV-VIS difference spectra of EosFP at $\mathrm{p}^{1} \mathrm{H} 6.9$ and $\mathrm{cw}$ illumination at $405 \mathrm{~nm}$ and room temperature. A) Applying a homogeneous global fitting scheme, two components (green: $\mathrm{k} 1(1)$, red: $\mathrm{k} 1(2))$ were observed during a $140 \mathrm{~s}$ illumination period 'Phase 1'. Note the secondary axis for K1(1) (right Y axis). B) Spectral differences observed in darkness, following the previous 'Phase 1' illumination, designated 'Phase 2'. Two components (green: k2(1), red: k2(2)) were sufficient to fit the data globally

Next, we performed time resolved FTIR measurements of EosFP at $\mathrm{p}^{1} \mathrm{H} 6.9$ and $\mathrm{p}^{2} \mathrm{H} 6.9$ under comparable conditions of illumination at $405 \mathrm{~nm}$ in ${ }^{1} \mathrm{H}_{2} \mathrm{O}$ and ${ }^{2} \mathrm{H}_{2} \mathrm{O}$. Two rate constants were retrieved for a 300s illumination period, $\mathrm{k} 1(1)=0.05 \mathrm{~s}^{-1}$ (green) and $\mathrm{k} 1(2)=0.014 \mathrm{~s}^{-1}$ (red) in ${ }^{1} \mathrm{H}_{2} \mathrm{O}$ (Fig 3A). It is noted that the value of k1(1) is an order of magnitude smaller than those measured with UV-VIS spectroscopy, due to a lower illumination intensity (Materials and Methods). 
However, the values of k1(2) are comparable between the UV-VIS and FTIR kinetics, which further supports its assignment to a thermal ('dark') reaction. While the k1(1) rate measured for TR-FTIR was smaller, it still separates sufficiently well from k1(2) with a three-fold difference in addition to showing distinct spectral differences (Fig 3A). The subsequent dark period of 140s 'Phase 2' yielded two rate constants of $k 2(1)=1.13 \mathrm{~s}^{-1}$ and $\mathrm{k2}(2)=0.009 \mathrm{~s}^{-1}$ (Fig. 3B). Measurements in ${ }^{2} \mathrm{H}_{2} \mathrm{O}$ yielded similar rate constants for Phase 1, with $\mathrm{k} 1(1)=0.053 \mathrm{~s}^{-1}$ and $\mathrm{k} 1(2)=0.019 \mathrm{~s}^{-1}$ (Figure 3C,D) as well as for Phase 2, k2(1) $=0.56 \mathrm{~s}^{-1}$ and $\mathrm{k} 2(2)=0.004 \mathrm{~s}^{-1}$ (Fig S2) although it was reproducibly and consistently noted that the 'Phase 2' amplitudes in ${ }^{2} \mathrm{H}_{2} \mathrm{O}$ (Fig. S2) were an order of magnitude smaller than those for 'Phase 2' of the ${ }^{1} \mathrm{H}_{2} \mathrm{O}$ measurements (Fig 3B). Since this difference in amplitudes was not observed for the UV-VIS measurements (Figs 2B,D), and no significant spectral alterations are noted in FTIR spectra (Figs 3B,D) the difference in illumination intensity, and consequent accumulation of intermediate is the most likely origin. Therefore, no significant Kinetic Isotope Effects were observed for either 'Phase 1' or 'Phase 2' in both the UV-VIS and FTIR studies. 

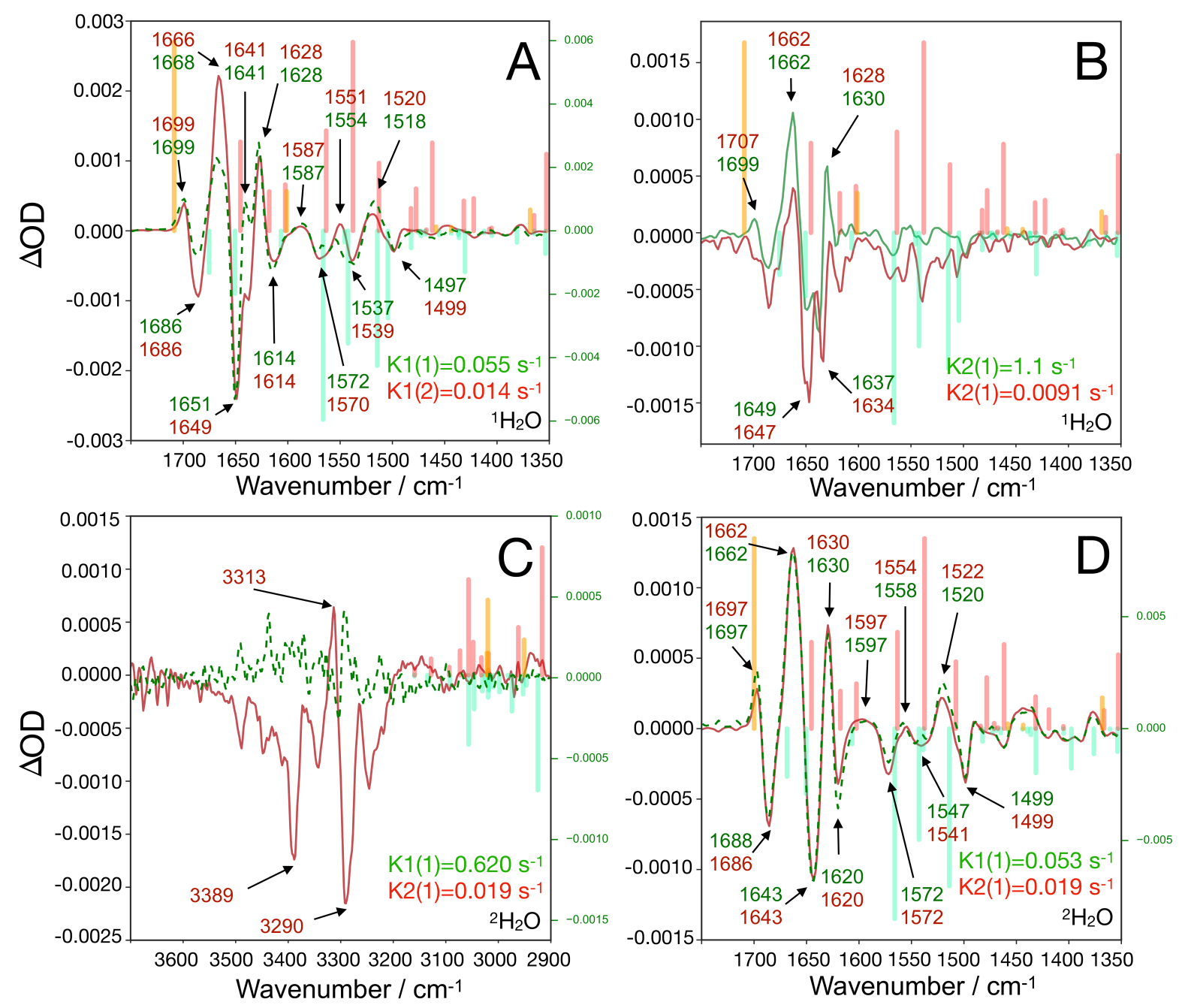

Figure 3. Globally fitted time resolved FTIR light-minus-dark difference spectra of EosFP at $\mathrm{p}^{1} \mathrm{H}$ 6.9 and $\mathrm{p}^{2} \mathrm{H} 6.9$ with $\mathrm{cw}$ illumination at $405 \mathrm{~nm}$ and room temperature. A) A homogeneous global fitting for measurements in ${ }^{1} \mathrm{H}_{2} \mathrm{O}$ and 300 s continuous illumination retrieved two components. Stick spectra for GA and RA structures in Fig. 1 are included from harmonic frequency calculations at B3LYP/6-311+G* level and scaled (SI; Table S1,S2). Note the secondary axis for K1(1). B) The subsequent 'Phase 2' period of 140s in darkness yielded two components. C,D) In ${ }^{2} \mathrm{H}_{2} \mathrm{O}$ two components were found for 300 s illumination, including also 
signals in the high frequency C-H stretching region. The subsequent 'Phase 2' period showed two components, albeit with weak signals (Fig S2).

The ground state that reacts under illumination, which is predominantly in the GA state is characterized by major bleaches at $\left.\left({ }^{1} \mathrm{H}_{2} \mathrm{O}\right) /{ }^{2} \mathrm{H}_{2} \mathrm{O}\right)$ values: $1686(-) / 1687(-) \mathrm{cm}^{-1}, 1650(-) / 1643(-)$ $\mathrm{cm}^{-1}, 1638(-) / 1643(-) \mathrm{cm}^{-1}, 1614(-) / 1620(-) \mathrm{cm}^{-1}, 1570(-) / 1571(-) \mathrm{cm}^{-1}, 1539(-) / 1540(-) \mathrm{cm}^{-1}$ and 1498(-)/1498(-) $\mathrm{cm}^{-1}\left({ }^{1} \mathrm{H}_{2} \mathrm{O} /{ }^{2} \mathrm{H}_{2} \mathrm{O}\right)$ (Figs 3A,D). The product state, which is predominantly the RA state, is characterized by major positive signals at $1699(+) / 1697(+) \mathrm{cm}^{-1}, 1666(+) / 1662(+) \mathrm{cm}^{-1}$, 1642(+)/(N.A.) $\mathrm{cm}^{-1}, \quad 1628(+) / 1630(+) \mathrm{cm}^{-1}, 1587(+) / 1597(+) \mathrm{cm}^{-1}, 1551(+) / 1554(+) \mathrm{cm}^{-1}$, $1519(+) / 1521(+) \mathrm{cm}^{-1}$ and $1489(+) / 1490(+) \mathrm{cm}^{-1}\left({ }^{1} \mathrm{H}_{2} \mathrm{O} /{ }^{2} \mathrm{H}_{2} \mathrm{O}\right)$ (Figs 3A,D). As the GA state corresponds to the anionic ground state of the cis-chromophore of the Green Fluorescent Protein and Dronpa, existing mode assignments ${ }^{18-23}$ may be directly extended to the GA form of EosFP. The chromophore imidazolinone $\mathrm{C}=\mathrm{O}(2)$ (Fig.1) stretching mode is found at 1686/1687 $\mathrm{cm}^{-1}$ $\left({ }^{1} \mathrm{H}_{2} \mathrm{O} /{ }^{2} \mathrm{H}_{2} \mathrm{O}\right)$ having no isotope sensitivity, close to frequencies of $1672 \mathrm{~cm}^{-1}$ and $1688 \mathrm{~cm}^{-1}$, of anion chromophores in GFP and Dronpa ${ }^{24}$, respectively. Harmonic frequency calculation predicts a $5 \mathrm{~cm}^{-1}$ downshift for the $\mathrm{C}=\mathrm{O}(2)$ stretching frequency of RA relative to $\mathrm{GA}$ (Table S1), such that the $1666(+) / 1662(+) \mathrm{cm}^{-1}$ band is assigned to the chromophore $\mathrm{C}=\mathrm{O}(2)$ mode of RA. The $1699(+) / 1697(+) \mathrm{cm}^{-1}$ carbonyl mode has only very small ${ }^{1} \mathrm{H} /{ }^{2} \mathrm{H}$ sensitivity and is thus not assigned to a carboxylic group additionally being too low in frequency ${ }^{25}$. Instead, this mode identifies the $\mathrm{NH}_{2}-\mathrm{C}=\mathrm{O}$ product formed after photoinduced cleavage of the peptide bond at $\mathrm{C} \alpha$ of His-62. Since this mode is already present in the first reaction $\mathrm{k}(1) 1$ during illumination, this confirms that the photoinduced peptide bond cleavage is completed and followed by the rearrangement: (Scheme 3) 


$$
\mathrm{HO}-\mathrm{C}=\mathrm{NH} \stackrel{\mathrm{K} 1(1)}{\longrightarrow} \mathrm{O}=\mathrm{C}-\mathrm{NH}_{2}
$$

Scheme 3

The GA 1650(-)/1643(-) $\mathrm{cm}^{-1}$ signal appears in the region that is characteristic for Amide-I absorption. Indeed, the photoinduced cleavage of $\mathrm{C} \alpha$ of His-62 removes a single amide bond. Both the ${ }^{1} \mathrm{H} /{ }^{2} \mathrm{H}$ shift and the intensity which corresponds to less than a percent of the total Amide-I absorption, supports the assignment of this mode to Amide-I of His-62 in the reactant (GA) state. Furthermore, the frequencies are in the ranges of $\alpha$-helix or disordered polypeptide Amide-I vibration ${ }^{25}$. The RA modes are interpreted not to include an associated product band, as expected. The $1638(-) / 1628(+) \mathrm{cm}^{-1}$ downshift feature in ${ }^{1} \mathrm{H}_{2} \mathrm{O}$ (Fig. 3A) can be assigned to a chromophore $\mathrm{C}=\mathrm{C}(1)$ stretching mode, which combines with the Amide-I bleach at $1643(-) \mathrm{cm}^{-1}$ in ${ }^{2} \mathrm{H}_{2} \mathrm{O}$ (Fig 3D).

Calculations support the assignment from the predicted $4 \mathrm{~cm}^{-1}$ downshift in RA relative to GA and lack of ${ }^{1} \mathrm{H} /{ }^{2} \mathrm{H}$ sensitivity (Table S1). Following the mode labeling introduced by He et al ${ }^{23}$, the 'phenol-1' mode is located at $1570(-) / 1571(-) \mathrm{cm}^{-1}$ in GA and $1551(+) / 1554(+) \mathrm{cm}^{-1}$ in RA (Fig. 3A,B,D). This is further supported by a predicted downshift in RA relative to GA, although only by $3 \mathrm{~cm}^{-1}$ (Table S1). Following the highest frequency mode in the fingerprint region of the RA state belonging to $\mathrm{C}=\mathrm{O}(2)$ stretching, the next high frequency mode is expected to belong to the photochemical formation of the $\mathrm{C} \alpha=\mathrm{C} \beta$ bond which is responsible for extending the conjugated system. The induced absorption signal at $1642(+) \mathrm{cm}^{-1}$ is proposed to belong to the $\mathrm{C} \alpha=\mathrm{C} \beta$ stretch, and is resolved only in the ${ }^{1} \mathrm{H}_{2} \mathrm{O}$ measurements (Fig. 3A) as it is obscured by the strong Amide-I bleach in ${ }^{2} \mathrm{H}_{2} \mathrm{O}$ (Fig. 3B). The high frequency and localised mode character is supported by frequency calculations (SI; Table S1). The observation of this product (Scheme 4) 
agrees with Scheme 3, as the $\mathrm{C}=\mathrm{C}(2)$ formation is expected to precede the formation of the $\mathrm{NH}_{2}-$ $\mathrm{C}=\mathrm{O}$ group. Both the $\mathrm{C}=\mathrm{C}(2)$ (scheme 4) and the $\mathrm{NH}_{2}-\mathrm{C}=\mathrm{O}$ (scheme 3 ) formation are observed in the k1(1) reaction.

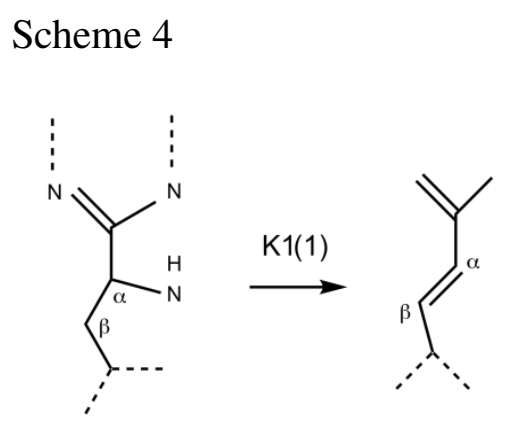

Bands at $1614(-) / 1620(-) \mathrm{cm}^{-1}$ and $1587(+) / 1597(+) \mathrm{cm}^{-1}$ (Fig. 3A,B,D) are tentatively assigned to 'phenol-2' modes in GA and RA, respectively. Interestingly, in GFP and the chromophore model compound HBDI it is known that this mode is not detected in the anion state due to its low cross section but it is weakly observed in the neutral protonated form. In support of the assignments to phenol-2 in GA and RA of EosFP, harmonic frequency calculations predict normal modes with phenol-2 character with significant intensity, absent also in HBDI calculations (Table S1). The next mode that is commonly designated as having $\mathrm{C}=\mathrm{N}$ stretching character ${ }^{23-24}$ from the imidazolinone group, is tentatively assigned to the $1539(-) / 1540(-) \mathrm{cm}^{-1}$ band in GA. Frequency calculation interestingly indicates a $52 \mathrm{~cm}^{-1}$ downshift of a $\mathrm{C}=\mathrm{N}$ stretching mode in the RA form relative to GA, which causes a mode progression reversal for this mode and the next phenol containing mode ('Phenol-3') in RA relative to GA (as well as the anion states of GFP and HBDI ${ }^{19-20,23-24}$ ). A possible assignment for the RA C=N stretching mode is thus $1445(+) / 1445(+) \mathrm{cm}^{-1}$ (Fig 3). Assignment of an Amide-II bleach in GA that corresponds to the main Amide-I bleach at $1650(-) / 1643(-) \mathrm{cm}^{-1}$ is proposed but is not unambiguous. The 
Amide-II signal is expected near $1550(-) / 1480(-) \mathrm{cm}^{-1}\left({ }^{1} \mathrm{H}_{2} \mathrm{O} /{ }^{2} \mathrm{H}_{2} \mathrm{O}\right){ }^{25}$, so that it is possible that it contributes to the chromophore $\mathrm{C}=\mathrm{N}$ mode at $1539(-) \mathrm{cm}^{-1}$ in ${ }^{1} \mathrm{H}_{2} \mathrm{O}$, which is however mostly unaltered in ${ }^{2} \mathrm{H}_{2} \mathrm{O}$ (Figs. 3A,D). A candidate mode in ${ }^{2} \mathrm{H}_{2} \mathrm{O}$ could be at $1461(-) \mathrm{cm}^{-1}$, although this band is also present in ${ }^{1} \mathrm{H}_{2} \mathrm{O}$. Any contribution from Amide-II bleaching is therefore clearly very weak in the difference spectra, whereas the amide-I mode is strongly identified. Thus, mode assignments in the fingerprint region can be proposed for the majority of the RA and GA modes.

While FTIR difference measurements in ${ }^{1} \mathrm{H}_{2} \mathrm{O}$ in the high frequency region $3700-2900 \mathrm{~cm}^{-1}$ were made with the aim of identifying the corresponding Amide-A mode near $\sim 3300 \mathrm{~cm}^{-12}{ }^{25}$, these were inconclusive due to the low transmission for the sample conditions. However, in ${ }^{2} \mathrm{H}_{2} \mathrm{O}$ and $\mathrm{p}^{2} \mathrm{H} 6.9$ conditions, a series of difference features were resolved following illumination. While signals associated with k1(1) were smaller and dominated by $3386(-) \mathrm{cm}^{-1}$ and $3288(-) \mathrm{cm}^{-}$ ${ }^{1}$ signals, the second $\mathrm{k1}(2)$ reaction showed up to seven bleach signals at 3540(-) 3492(-), 3462(-), 3387(-), 3340(-), 3288(-) and 3246(-) $\mathrm{cm}^{-1}$ (Fig 3C). Corresponding features for RA were observed at generally downshifted frequencies 3520(+) 3478(+), 3458(+), 3370(+), 3318(+), 3265(+) and 3180(+) $\mathrm{cm}^{-1}$. Frequency calculation predicts downshifts for seven C-H stretching frequencies, but predict between $3160 \mathrm{~cm}^{-1}$ and $3020 \mathrm{~cm}^{-1}$ after scaling (Table S1). The $3340(-) / 3318(+) \mathrm{cm}^{-1}, 3288(-) / 3265(+) \mathrm{cm}^{-1}$ bands are tentatively assigned to the two $\mathrm{sp} 2$ configuration C-H stretching modes of His 62 imidazole group, assuming complete exchange to ${ }^{2} \mathrm{H}_{2} \mathrm{O}$ and additionally from the frequency correspondence between the k1(1) and k1(2) spectra. As these are predominant in reaction $\mathrm{k} 1(2)$, this would suggest that modification of the imidazole ring follows the formation of $\mathrm{C} \alpha=\mathrm{C} \beta$ seen in $\mathrm{k} 1(1)$ from the mid-IR region. The His 62 imidazole ring resides in a non-polar environment, but the $\mathrm{N} \delta$ - $\mathrm{H}$ group forms a contact with the carbonyl of Phe 61 at $3.3 \AA$ distance ${ }^{4}$. The newly generated sp2 C-H stretches of the $\mathrm{C} \alpha=\mathrm{C} \beta$ 
fragment are predicted from calculation at frequencies lower than those for the imidazole $\mathrm{C}-\mathrm{H}$ stretches, but the major product bands of k1(1) at high frequency are at $3225(+) \mathrm{cm}^{-1}, 3295(+) \mathrm{cm}^{-}$ ${ }^{1}$ and $3438(+) \mathrm{cm}^{-1}$, the first two of which could belong to these groups (Figure 3C)

Other high frequency features should potentially be assigned to $\mathrm{N}-\mathrm{H}$ and $\mathrm{O}-\mathrm{H}$ stretching modes for groups that had not fully exchanged or could belong to remaining HOD. They cannot include the chromophore phenolic $\mathrm{OH}$ at $\mathrm{pH}$ 6.9. A potential $\mathrm{NH}_{2}-\mathrm{O}-\mathrm{H}$ intermediate following peptide bond cleavage (scheme 3) is also unlikely to contribute since the product $\mathrm{C}=\mathrm{O}$ carboxylate is already observed in the k1(1) reaction (Figure 3). Possibly, a carboxyl overtone could contribute, but compared to the signals in the $\mathrm{C}=\mathrm{O}$ stretching fundamental region, the intensities are likely too high. Thus non-, or slow-exchanging N-H groups can also be responsible for the shift features in the high frequency region. These could include the $\mathrm{NH}_{2}-\mathrm{C}=\mathrm{O}$ product (scheme 3 ), the His 62 imidazole sidechain, and amide groups in the chromophore vicinity.

Having described the spectral kinetics it is of interest to consider the corresponding spectral differences between $\mathrm{k}(1) 1$ and $\mathrm{k}(1) 2$ seen in both UV-VIS and FTIR measurements at $\mathrm{p}^{1} \mathrm{H} 6.9$ and $\mathrm{p}^{2} \mathrm{H}$ 6.9. The UV-VIS measurements clearly indicate that the RA is not fully formed in the first reaction k1(1) under illumination, lacking much cross-section near $571 \mathrm{~nm}$ and having blueshifted absorption near 562-568 nm. Interestingly, it is seen that the FTIR difference spectra of k1(1) and k1(2) differ predominantly in the amplitudes of both the GA and RA C=O(1) stretching modes, while their frequencies are not modified (Fig 2A). This difference was less evident in ${ }^{2} \mathrm{H}_{2} \mathrm{O}$, but possibly due to kinetics changes relative to ${ }^{1} \mathrm{H}_{2} \mathrm{O}$. 
Since the $1699(+) \mathrm{cm}^{-1}$ product band is present in the $\mathrm{k} 1(1)$ product, the reaction must involve complete cleavage of the peptide bond at C $\alpha$ of His-62 (Scheme 3). Furthermore, the frequency positions in the $1750-1100 \mathrm{~cm}^{-1}$ region of the products of $\mathrm{k} 1(1)$ and $\mathrm{k} 1(2)$ under illumination are unmodified, indicating strongly that the covalent and electronic structure of RA is fully formed on the phenol, imidazolinone, the ethylenic bond as well as the $\mathrm{C} \alpha=\mathrm{C} \beta$ product bond and $\mathrm{NH}_{2}-$ $\mathrm{C}=\mathrm{O}$ group. Differences in the dielectric environment of the $\mathrm{C}=\mathrm{O}(2)$ group in both the GA and RA distinguish the k1(1) and k1(2) phase, as evaluated from the reduced intensity in k1(1) (Figure 3A). In ${ }^{1} \mathrm{H}_{2} \mathrm{O}$, an additional spectral difference is the small modification (minor downshift) of the Amide-I mode at $1650(-) \mathrm{cm}^{-1}$ in the $\mathrm{k} 1(2)$ reaction compared to the initial $\mathrm{k} 1(1)$ reaction, additionally affecting the $1642(+) \mathrm{cm}^{-1}$ appearance. This suggests that $\mathrm{k} 1(1)$ resolves the Amide-I response of an intermediate that is modified relative to the reactant dark state. Specifically, we consider the possibility of a precursor such as considered in Scheme 2 that would include a charge near the $\mathrm{C} \alpha-\mathrm{C} \beta$ amide bond.

Here, we report for the first time that subsequent to illumination the conversion of GA to RA proceeds thermally on the minute timescale in darkness (Figs 2B,3B, S2). Both UV-VIS and FTIR measurements of the dark 'Phase 2' are dominated by spectral changes that can be assigned to the GA and RA states, and are essentially similar to the k(1)2 reaction of 'Phase 1' (Figs 2,3). The thermal reactions $\mathrm{k} 2(1)$ and $\mathrm{k} 2(2)$, which also contribute to $\mathrm{k} 1(2)$, have a dominating contribution from the $1685(-) \mathrm{cm}^{-1} / 1668(+) \mathrm{cm}^{-1}$ feature assigned to the chromophore $\mathrm{C}=\mathrm{O}(2)$ mode, indicating modification of oscillator strength of both the GA reactant as well as the RA product. Thus, we identify a meta-stable reaction intermediate which is able to depopulate the GA and subsequently proceeds to form the RA product. This intermediate has very small cross- 
section in both the UV-VIS and FTIR spectral regions and is thus not spectroscopically identifiable at $\mathrm{p}^{1} \mathrm{H} / \mathrm{p}^{2} \mathrm{H} 6.9$.

Transient UV-VIS and FTIR studies at $p^{1} H / p^{2} H 5.1$ near the $p K a$ values of green and red chromophores

While the presented measurements at $\mathrm{p}^{1} \mathrm{H} / \mathrm{p}^{2} \mathrm{H} 6.9$ are significantly above the pKa values of both green and red chromophores ${ }^{1}$, the $405 \mathrm{~nm}$ illumination transforms the minor green neutral (GN) chromophore population directly such that the dominating anion contributions to the difference spectra are recorded following thermal protonation. We therefore examined conditions at $\mathrm{p}^{1} \mathrm{H} / \mathrm{p}^{2} \mathrm{H} 5.1$ chosen to be at or near the $\mathrm{pKa}$ values of the reactant and product. Kinetic UVVIS measurements in ${ }^{1} \mathrm{H}_{2} \mathrm{O}$ revealed three components in the 'Phase 1 ' illumination period, with a significantly accelerated initial component $\mathrm{k} 1(1)=7.9 \mathrm{~s}^{-1}$, followed by $\mathrm{k} 1(2)=0.048 \mathrm{~s}^{-1}$ and $\mathrm{k} 1(3)=0.040 \mathrm{~s}^{-1}$ (Fig 4A). Spectral differences allowed separation of $\mathrm{k} 1(2)$ and $\mathrm{k} 1(3)$ and in repeat experiments were occasionally fitted to several-fold different rate constants, maintaining spectral characteristics. This acceleration of the $\mathrm{k} 1(1)$ component relative to $\mathrm{pH} 6.9$ (Fig. 3A) likely reflect the differences in ground state concentration for the GN species from the increased optical excitation rate under conditions of ensemble attenuation.

The fast k1(1) component shows bleaching at 384(-) nm (GN) and 504(-) nm (GA), with amplitudes that reflect the ground state absorption spectrum, indicating that thermal protonation of GA is faster than the photoinduced rate of GN conversion. Repeat measurements in ${ }^{1} \mathrm{H}_{2} \mathrm{O}$ at 
$\mathrm{p}^{1} \mathrm{H} / \mathrm{p}^{2} \mathrm{H} 5.1$ resulting in faster $\mathrm{k} 1(1)$ rates near $17 \mathrm{~s}^{-1}$ resolved RA product absorption at 571(+) $\mathrm{nm}$, while examples for slower measurements at $\mathrm{k} 1(1)=5.3 \mathrm{~s}^{-1}$ lacked the RA product (Fig S4). The measurement shown in Fig. 4 with $\mathrm{k} 1(1)=7.9 \mathrm{~s}^{-1}$, presents both an intermediate rate and an intermediate RA product amplitude for K1(1).This suggests that the light-driven reactions with illumination of GN create the RN directly, which is followed by thermal deprotonation at low $\mathrm{pH}$ $=5.1$ with a rate slower than $17 \mathrm{~s}^{-1}$. Measurements performed in ${ }^{2} \mathrm{H}_{2} \mathrm{O}$ were essentially equivalent with regard to kinetics and spectral differences except perhaps a reduced product absorption of RA at $572(+)$ nm in both $\mathrm{k} 1(1)$ and $\mathrm{k} 1(3)$ reactions relative to ${ }^{1} \mathrm{H}_{2} \mathrm{O}$ (Fig S3).

The products of $\mathrm{k} 1(1)$ are seen at $309(+) \mathrm{nm}$ and $433(+) \mathrm{nm}$, but both bleaches and induced bands have about five-fold lower amplitude compared to k1(2) and k1(3), so represents a minor population (Fig 4).The possible assignment of the $434(+) \mathrm{nm}$ band to $\mathrm{RN}$ is tentative as it is significantly blue-shifted from the final RN product at $445(+) \mathrm{nm}$. The intermediate reaction k1(2) shows red-shifted product absorption of both $\mathrm{RN}$ bands at $330\left(^{+}\right) \mathrm{nm}$ and $358(+) \mathrm{nm}$ in addition to unmodified RA at $571(+) \mathrm{nm}$. A reproducible characteristic of $\mathrm{k1}(2)$ is the reduced amplitude of GA bleaching at 507(-) nm relative to GN bleaching at 388(-) nm, although a more likely interpretation is that the shoulder seen near $490(+) \mathrm{nm}$ represents a product absorption (Intermediate $\mathrm{I}_{490 \mathrm{~mm}}$ ) specific to $\mathrm{k} 1(2)$ that raises the level of the GA bleach (Fig. 4). The third reaction k1(3) recovers the initial bleaching amplitude ratio of GA and GN likely due to decay of the $\mathrm{I}_{490 \mathrm{~nm}}$ intermediate, while both $\mathrm{RN}$ products at $321(+) \mathrm{nm}$ and $445\left(^{+}\right) \mathrm{nm}$ blue-shift again relative to $\mathrm{k1}(2)$, and the RA product is again unmodified at $571(+) \mathrm{nm}$ (scheme 5).

Scheme 5 


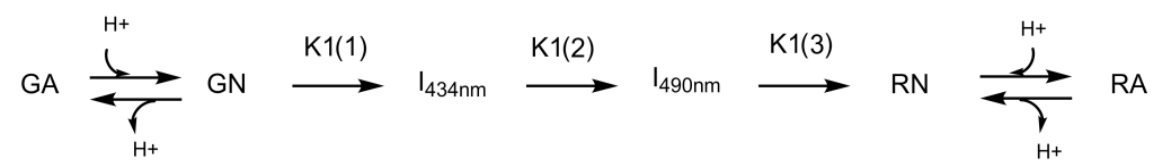

The subsequent 'Phase 2 ' in darkness proceeds with similar rate constant as compared to ${ }^{1} \mathrm{H}_{2} \mathrm{O}$, however the spectral evolution of the dark Phase 2 is markedly different from that of the illumination period Phase 1 (Fig 4B). Two components with essentially the same spectral differences appear to show GA bleaching at 507(-) nm, but completely lack the corresponding GN bleaching. This could potentially be due to an intrinsic limit to the rate of thermal protonation of the phenolic oxygen on the 50s timescale of the Phase 2 measurement, which is however considered to be unlikely. Strikingly, shift-features of the S1 and S2 transitions of RA are seen in Phase 2 at 555(+) nm/583(-) nm and 302(+) nm/342(-) nm, respectively. These shift features modify the RA product at 571(+) nm (S1) and $312 \mathrm{~nm}$ (S2) formed in Phase 1. Weaker RN absorption near $440(+) \mathrm{nm}$ is identified as well in Phase 2. Together with FTIR spectra of Phase 2 (below), it is concluded that these low $\mathrm{pH}$ UV-VIS spectra in contrast to the high $\mathrm{pH}$ measurements are dominated by Stark-shifted features, thus identifying a charged intermediate in the dark reactions. 


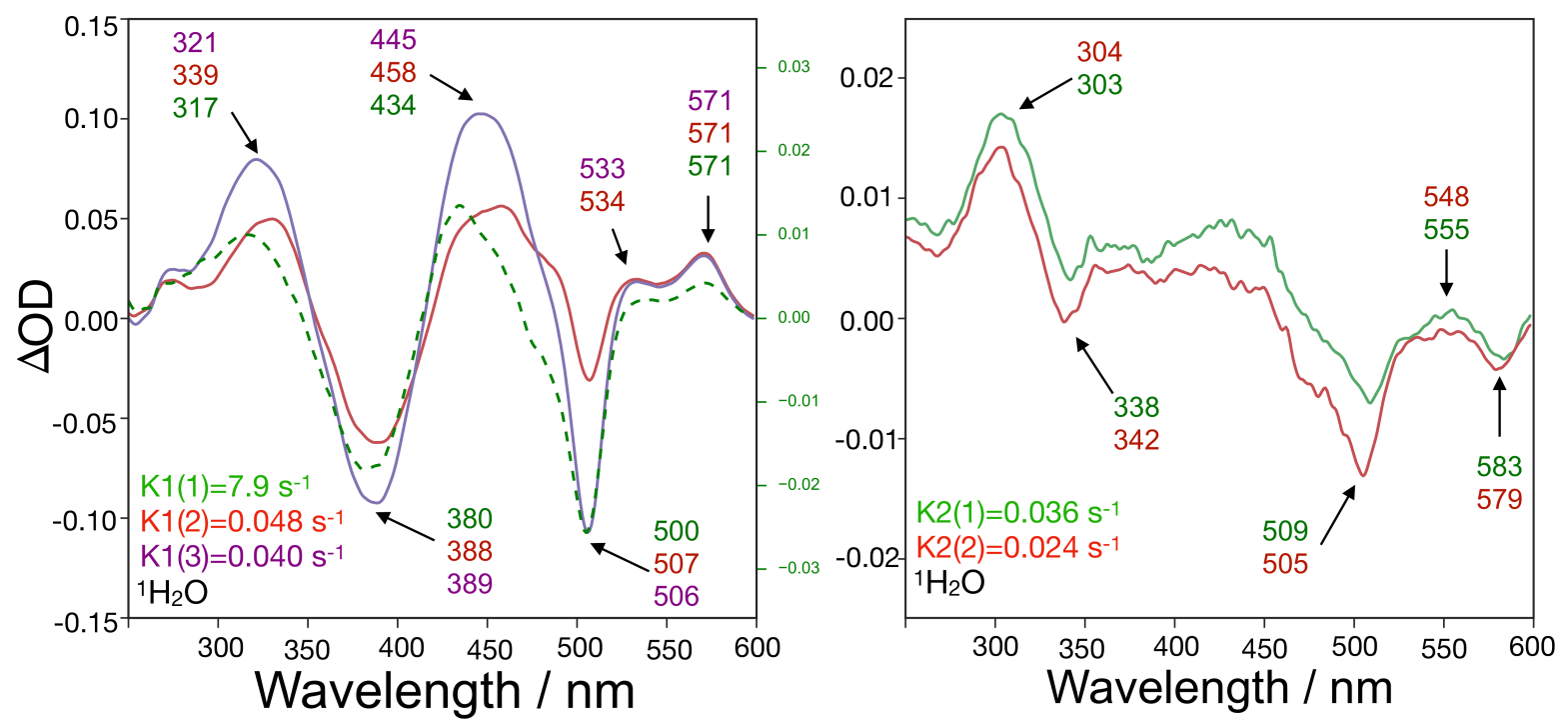

Figure 4. Globally fitted time resolved UV-VIS difference spectra of EosFP at $\mathrm{p}^{1} \mathrm{H} 5.1$ and $\mathrm{cw}$ illumination at $405 \mathrm{~nm}$ and room temperature. A) Applying a homogeneous global fitting scheme, three components were observed during a 90s illumination period 'Phase 1'. Note the secondary axis for k1(1). B) Spectral differences observed in darkness, following the previous 'Phase 1' illumination, designated 'Phase 2'.

Time resolved FTIR measurements in ${ }^{1} \mathrm{H}_{2} \mathrm{O}$ and ${ }^{2} \mathrm{H}_{2} \mathrm{O}$ at $\mathrm{p}^{1} \mathrm{H} / \mathrm{p}^{2} \mathrm{H} 5.1$ show three components for Phase 1 under illumination (Fig. 5). However the spectrum for the first phase k1(1) seen by UV-VIS spectroscopy could not be resolved by FTIR with a fitted rate k1(1)=1.0 $\mathrm{s}^{-1}$ with $10 \mathrm{~s}$ acquisition time (Fig. S5). While the initial IR absorption differences indicated a rapid initial reaction as with the UV-VIS measurements, global fitting to resolve the phase reaction was not possible (Fig. S5). As with the UV-VIS kinetics measurements, the amplitudes of k1(1) were seen to be significantly smaller than those of $\mathrm{k} 1(2)$ and $\mathrm{k} 1(3)$, approximately $5-10$-fold. The following two reactions $\mathrm{k1}(2)$ and $\mathrm{k1}(3)$ correspond to RA gain and GA loss and contain major 
features also seen in the high $\mathrm{pH}$ measurements (Fig. 3, 5). The protonated and anionic species are at about equal concentrations in both reactant and product near pKa, however the infrared cross sections for the anions are much stronger and dominate the difference spectra, as is also seen in GFP ${ }^{18}$ and Dronpa ${ }^{24}$. Aside from the differences in the $\mathrm{C}=\mathrm{C}$ region, the spectra at $\mathrm{pH} 5.1$ in Phase 1 during illumination almost fully coincide with the spectra at $\mathrm{pH} 6.9$ and few additional bands belonging to the neutral green and neutral red chromophores are detected (Figs. $3,5)$

The thermal reactions in Phase 2 proceed with $\mathrm{k} 2(1)=0.06 \mathrm{~s}^{-1}, \mathrm{k} 2(2)=0.014 \mathrm{~s}^{-1}$ in ${ }^{1} \mathrm{H}_{2} \mathrm{O}$ and predominantly k2(2) $=0.0058 \mathrm{~s}^{-1}$ in ${ }^{2} \mathrm{H}_{2} \mathrm{O}$ (Figure 5B,E,F). The spectra for ${ }^{1} \mathrm{H}_{2} \mathrm{O}$ and ${ }^{2} \mathrm{H}_{2} \mathrm{O}$ measurements are significantly different for Phase 2 (Figure 5E,F). The major spectral differences are already observed in the slow k1(2) reactions of Phase 1 of both ${ }^{1} \mathrm{H}_{2} \mathrm{O}$ and ${ }^{2} \mathrm{H}_{2} \mathrm{O}$ measurements that clearly contain dark reactions already (Fig 5 A,C,D). In ${ }^{2} \mathrm{H}_{2} \mathrm{O}$ the high frequency region resolved corresponding reactions (Figure 5C,E).

The $\mathrm{k1}(2)$ and $\mathrm{k1}$ (3) reactions in ${ }^{1} \mathrm{H}_{2} \mathrm{O}$ both contain bleaches of the GA state at $1688(-) \mathrm{cm}^{-1}$ and $1650(-) \mathrm{cm}^{-1}$, and product bands of the RA state at $1699(+) \mathrm{cm}^{-1}$ and $1666(+) \mathrm{cm}^{-1}$ (Figure 5A). Spectral differences between the $\mathrm{k} 1(2)$ and $\mathrm{k} 1(3)$ reactions can be attributed to contributions in $\mathrm{k} 1(3)$ of the thermal reactions $\mathrm{k} 2(1)$ and $\mathrm{k} 2(2)$. Notable differences are the positions of the $\mathrm{C}=\mathrm{C}$ product bands at $1639(+) \mathrm{cm}^{-1}(\mathrm{k} 1(1))$ and $\left.1630(+) \mathrm{cm}^{-1}(\mathrm{k} 1(2))\right)$ (Fig. 5A). Further contributions to $\mathrm{k} 1(2)$ of spectral differences belonging to thermal reactions include $1527(-) \mathrm{cm}^{-1}, 1627(-) \mathrm{cm}^{-1}$, $1566(+) \mathrm{cm}^{-1}, 1616(+) \mathrm{cm}^{-1}$, in addition to the $1639(+) \mathrm{cm}^{-1} \mathrm{C}=\mathrm{C}$ mode, which are seen in both the k2(1) and k2(2) reactions of Phase 2 (Fig. 5B). Compared to the measurements at $\mathrm{pH}$ 6.9, 
differences primarily involve the frequency upshifts of the $1625(-) \mathrm{cm}^{-1} / 1639(+) \mathrm{cm}^{-1} \mathrm{C}=\mathrm{C}$ mode in the thermal process contribution to k1(3) and additional spectral features of Phase 2 (Figure 4,5). At pH6.9, the Phase 2 differences of FTIR have much smaller contributions from these $\mathrm{C}=\mathrm{C}$ bands, whereas the chromophore $\mathrm{C}=\mathrm{O}$ mode dominates ((Fig 5B).

Thus, the protonation difference between $\mathrm{pH} 6.9$ and $\mathrm{pH} 5.1$ inverts the sequence of events for the formation of $\mathrm{C}=\mathrm{C}$ bands: At high $\mathrm{pH}$, the first $\mathrm{k1}(1)$ reaction preferentially creates the newly formed $\mathrm{C} \alpha=\mathrm{C} \beta$ double bond assigned to the $1639(+) \mathrm{cm}^{-1}$ band, followed by formation in $\mathrm{k} 1(2)$ of the chromophore ethylenic downshifted bond at $1628(+) \mathrm{cm}-1$ (Figs 3,5). While this is confirmed for ${ }^{1} \mathrm{H}_{2} \mathrm{O}$, the ${ }^{2} \mathrm{H}_{2} \mathrm{O}$ high $\mathrm{pH}$ measurement did not resolve the $1639(+) \mathrm{cm}^{-1}$ feature (Fig. 3). This is supported by UV-VIS kinetics measurement which showed that at $\mathrm{pH} 6.9$ in both ${ }^{1} \mathrm{H}_{2} \mathrm{O}$ and ${ }^{2} \mathrm{H}_{2} \mathrm{O}$ the first reaction $\mathrm{k}(1) 1$ does create a red-shifted absorption, but at 566(+) nm and much reduced cross-section compared to the final RA product absorption at 571(+) nm (Figure 2). In contrast, and in agreement with the assignments from FTIR, at pH 5.1 the first reaction $\mathrm{k}(1) 1$ creates a RA product although at reduced amplitude (Figure 4). Thus, at low $\mathrm{pH}$ the formation of the fully extended conjugation that adds also the imidazole electrons is likely delayed, while the addition of the newly formed $\mathrm{C} \alpha=\mathrm{C} \beta$ double bond is not. Interestingly, the latter reaction is thought to require the anionic carboxylate of Glu 212 which is known to be absolutely required for green-to-red photoconversion ${ }^{4}$.

The protonation differences also strongly affect the thermal reactions seen in Phase 2: While at low pH intense bleach and product bands are detected, these are absent at high $\mathrm{pH}$ (Figure 4,5). These spectra are thus indicative of the accumulation of an intermediate at pH 5.1 only. In ${ }^{1} \mathrm{H}_{2} \mathrm{O}$ 
at $\mathrm{p}^{1} \mathrm{H} 5.1$ the spectra contain only weak $\mathrm{GA}(-) / \mathrm{RA}(+)$ chromophore contributions, while a 1682(-) $\mathrm{cm}^{-1}, 1627(-) \mathrm{cm}^{-1}$ and $1639(+) \mathrm{cm}^{-1}$ features indicates $\mathrm{C} \alpha=\mathrm{C} \beta$ product formation and what appears a decays of the RA modes dominant at pH 6.9 (Figure 5). Since these amplitudes are very small compared to the final product bands, the RA decay may indicate minor thermal protonation at low $\mathrm{pH}$ to establish the RN/RA equilibrium, indicating perhaps that the product in Phase 1 is primarily an anion chromophore. Additional modes in Phase 2 include 1523(-) $\mathrm{cm}^{-1}$, $1540(+) \mathrm{cm}^{-1}, 1560(+) \mathrm{cm}^{-1}$ and $1618(+) \mathrm{cm}^{-1}$ bands in ${ }^{1} \mathrm{H}_{2} \mathrm{O}$, and $1220(-) \mathrm{cm}^{-1}, 1531(-) \mathrm{cm}^{-1}$, $1456(+) \mathrm{cm}^{-1}$ and $1620(+) \mathrm{cm}^{-1}$ bands in ${ }^{2} \mathrm{H}_{2} \mathrm{O}$ (Figure 5). The prominent $1531(-) \mathrm{cm}^{-1}$ and $1456(+) \mathrm{cm}^{-1}$ bands are not likely to belong to chromophore modes as more bands would have been expected, but are tentatively assigned to protein contributions. Based on both the UV-VIS and FTIR spectra, an assignment to the formation in Phase 1 and subsequent decay in Phase 2 of a tyrosyl radical is considered. A primary consideration is the UV-VIS spectrum of the k1(1) reaction at $\mathrm{pH} 5.1$, which shows an induced absorbance at $427 \mathrm{~nm}$. The wavelength excludes the possibility of an assignment to tryptophan radical, expected at $\sim 520 \mathrm{~nm}{ }^{26-28}$, while an assignment to the Tyr-O. radical could be supported. In Cryptochrome and Photolyase long-lived tyrosyl radicals give rise to transient absorption at $\sim 410 \mathrm{~nm}^{29}$. While the $\mathrm{k} 1(1)$ reaction at $\mathrm{pH} 5.1$ shows a maximum at $427 \mathrm{~nm}$ this could appear more red-shifted due to combination with the bleach at $378 \mathrm{~nm}$ of the GN chromophore, which also appears blue-shifted relative to k1(2) and k1(3) spectra. Furthermore, FTIR difference spectra of tyrosyl radical at pH 12 have been reported ${ }^{30}$. An important reporter is the $\mathrm{CO}$ stretching $\mathrm{Y7a}$ band of the tyrosyl radical, reported with frequencies ranging from $1499 \mathrm{~cm}^{-1}$ to $1516 \mathrm{~cm}^{-131}$ and shown to be sensitive to the dielectric environment. A corresponding ring stretching mode Y8a of the tyrosyl group at $1570 \mathrm{~cm}^{-1}$ is generally weaker ${ }^{31}$. Thus, an assignment of the $1523(-) \mathrm{cm}^{-1} / 1531(-) \mathrm{cm}^{-1}\left({ }^{1} \mathrm{H}_{2} \mathrm{O} /{ }^{2} \mathrm{H}_{2} \mathrm{O}\right)$ feature in 
Phase 2 is tentatively assigned to the tyrosyl CO stretching mode in a strongly H-bonded environment (Figure 5 ). The strong $1456(+) \mathrm{cm}^{-1}$ band specifically seen in ${ }^{2} \mathrm{H}_{2} \mathrm{O}$ (Figure 5) may be a phenol mode, but no assignment can be well supported.

The spectral width of both the high frequency (Fig.5E) and fingerprint frequency (Fig. 5F) modes is significantly increased. This may be indicative of fast transverse dephasing that is linked to an increase of the dielectric strength of the environment, which has been studied in photoacids in liquids ${ }^{32}$. This would additionally suggest significant frequency shifts of the broadened modes, from the established correlation with spectral width ${ }^{32}$.

A further argument for the formation and decay of a radical in the protein environment is the observation of Stark-shift features in the Phase 2 UV-VIS spectra (Figure 4B). Specifically, these include up-shift features on the RA chromophore at 583(-) nm/559(+) nm and 355(-) nm/302(+) nm. Moreover, illumination subsequent to Phase 2 under conditions of partial conversion, reverses the Stark-shift features indicative of the renewed creation of radical species (Fig S6). The reaction k3(1) of 'Phase 3' shows Stark-shifted features on RA 566(-) nm/587(+) nm and small features on the RN bands, but in addition there are also Stark-shifted features on the reactant bands GA, 491(-) nm/512(+) nm and GN, 366(-) nm/395(+) nm (Fig S6). 

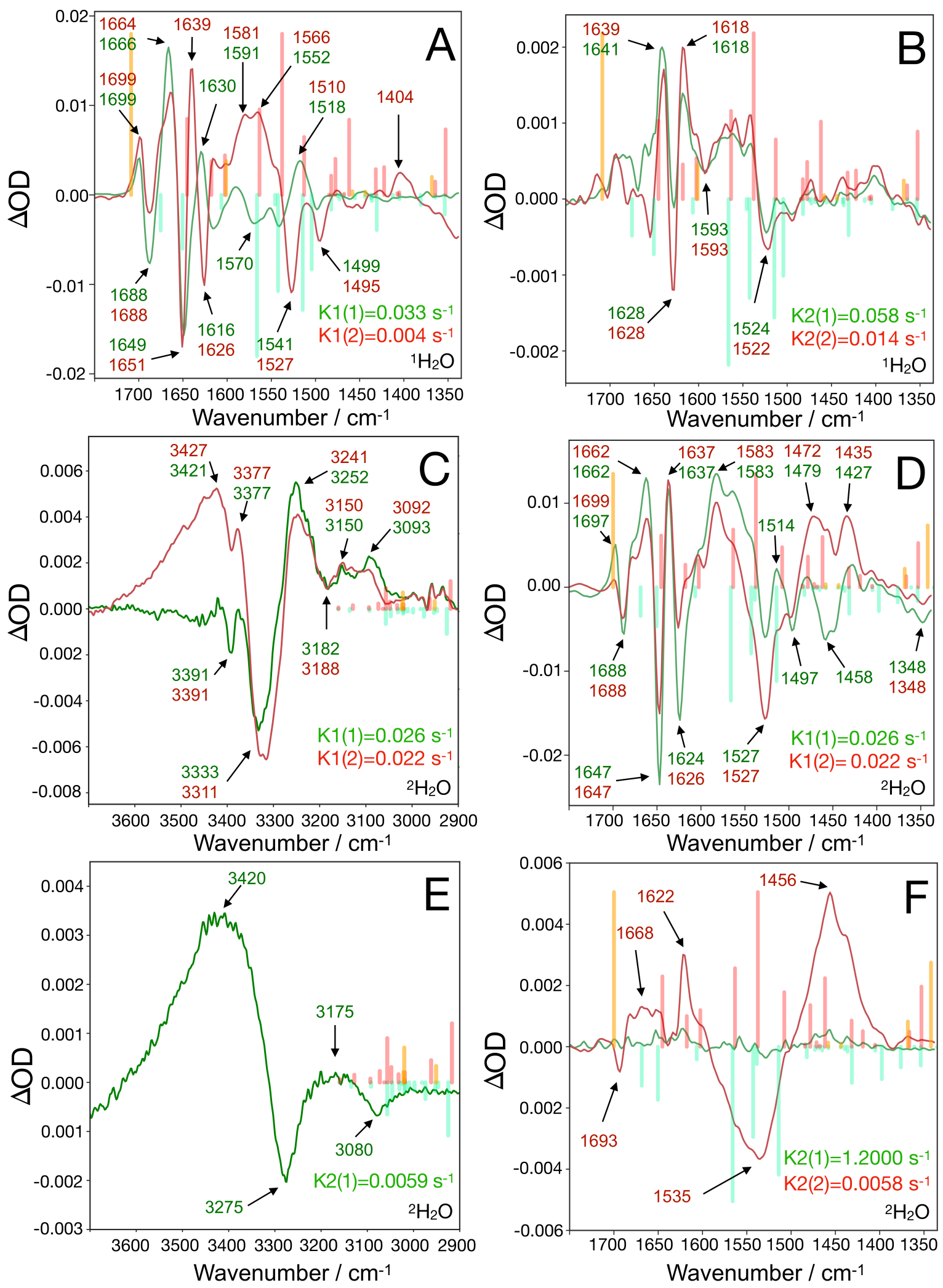
Figure 5. Globally fitted time resolved FTIR light-minus-dark difference spectra of EosFP at $\mathrm{p}^{1} \mathrm{H}$ 5.1 and $\mathrm{p}^{2} \mathrm{H} 5.1$ with $\mathrm{cw}$ illumination at $405 \mathrm{~nm}$ and room temperature. Stick spectra are those for RA and GA states that dominate the experimental spectra. A) A homogeneous global fitting for measurements in ${ }^{1} \mathrm{H}_{2} \mathrm{O}$ and 300s continuous illumination in Phase 1. B) The subsequent 'Phase 2' period of 140s in darkness in ${ }^{1} \mathrm{H}_{2} \mathrm{O}$. C, D) Difference spectra in ${ }^{2} \mathrm{H}_{2} \mathrm{O}$ during illumination in Phase 1 in the $1100-1750$ and $3700-2900 \mathrm{~cm}^{-1}$ regions. E,F) Difference spectra in ${ }^{2} \mathrm{H}_{2} \mathrm{O}$ during illumination in Phase 2 in the 1100-1750 and 3700-2900 $\mathrm{cm}^{-1}$ regions.

\section{Discussion}

The time-resolved measurements at pH 6.9 resolve a long-lived intermediate that FTIR showed already has the $\mathrm{C} \alpha=\mathrm{C} \beta$ double bond fully formed. However, the electronic spectrum associated with this intermediate differs from that of the final product. Specifically, it lacks significant cross-section, has blue-shifted absorption and lacks strong vibronic sidebands (Fig. 2A). The intermediate therefore may differ from the final RA product in the configuration of the imidazole group, which contributes $\mathrm{p}$ - and n- electrons to the extended conjugated system in the RA product. While careful analysis (using ${ }^{30}$ ) could not assign Histidine related signals in the FTIR difference spectra it is possible that these are weak and not seen in the presence of strong 
phenolate related IR differences that dominate the spectra. The FTIR data further provide direct evidence for the formation of the $\mathrm{NH}_{2}-\mathrm{C}=\mathrm{O}$ product group at Phe 61, thus confirming the hydroxyl deprotonation of the postulated intermediate ${ }^{7-9}$.

A potential candidate could be the proposed ' $\mathrm{C} 4$ ' intermediate as suggested by Lelimousin et al. from calculation ${ }^{7}$. Their proposed pathway however assumes a negative charge on the His 62 imidazole prior to the 'C4' intermediate, which is not supported by our observations, particularly the assignments of the FTIR difference spectra.

The FTIR spectra indicate that there are no net carboxylate protonation differences, from the lack of significant signal at $~ 1780-1720 / 1750-1710 \mathrm{~cm}^{-1}$ in ${ }^{1} \mathrm{H}_{2} \mathrm{O} /{ }^{2} \mathrm{H}_{2} \mathrm{O}$ spectra of $\mathrm{k}(1) 1$ or $\mathrm{k}(1) 2$ at $\mathrm{pH}$. Therefore, considering the essential role of $\mathrm{E} 212^{4-5}$, and the complete $\mathrm{C} \alpha=\mathrm{C} \beta$ double bond formation in k1(1), its carboxylate is deprotonated afterwards so that no differences from the dark state are detected. Furthermore, we show for the first time that subsequent to illumination, dark conversion from GA to RA continues, albeit with reduced amplitude. This is indicative of the presence of a light-accumulated reaction intermediate that is capable of transforming the GA reactant to its final RA product, and is taken as a first indication of the presence of a radical species that does not reside on the chromophore.

The measurements at pH5.1 reveal significant spectral differences from those at pH6.9 both in the UV-VIS and FTIR spectral regions. The most consistent assignment is that at reduced $\mathrm{pH}$ a tyrosyl radical accumulates in Phase 1, and subsequently decays in Phase 2. To support this we propose a tentative assignment of the induced absorption at $434 \mathrm{~nm}$ in $\mathrm{k} 1(1)$ at $\mathrm{pH} 5.5$ to the formation of a tyrosyl radical ${ }^{28}$. At $\mathrm{pH} 6.9$, weak induced absorption is also observed in the $~ 430$ $\mathrm{nm}$ region (Figure 2A). At pH5.5 the dark Phase 2 is dominated by electrochromic shift features, which likely obscures the weaker tyrosyl absorption decay. Taking into account the transient 
absorption seen at both pH6.9 and pH5.5 in the dark Phase 2, the following reaction scheme would be consistent with the accumulation of a tyrosyl radical with ground state re-formation under illumination, that subsequently is competent in oxidative transformation of the GN and GA ground state chromophores (Scheme 6,7).

Scheme 6

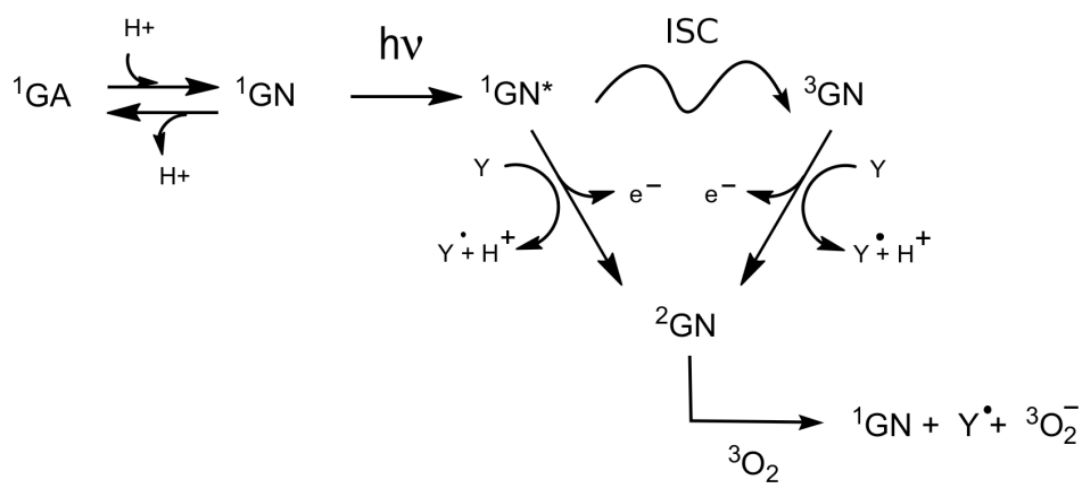

Scheme 7

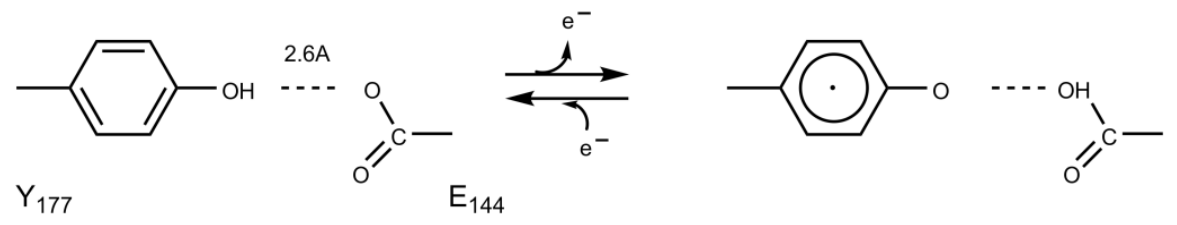

Both singlet ${ }^{1} \mathrm{GN}$ and triplet ${ }^{3} \mathrm{GN}$ state are indicated as oxidants of tyrosine, while the fast $\mathrm{k} 1$ (1) rate indicates the substantial quantum yield would support the ${ }^{1} \mathrm{NG}$ singlet state over the ${ }^{3} \mathrm{GN}$ triplet state (Scheme 6). In different fluorescent proteins, triplet state formation has been shown which is involved in the two-color 'primed' green-to-red photoconversion in various fluorescent proteins ${ }^{14-15}$. This is further supported by a recent report of low quantum yield triplet state formation in both EGFP and IrisFP ${ }^{33}$. Since our experimental observation shows rapid 
tyrosyl formation, the singlet state reaction shown in scheme 6 is more likely considering the low quantum yield of triplet state formation. The endproduct of the photooxidation (scheme 6) is experimentally seen to recover the ${ }^{1} \mathrm{GN}$ singlet chromophore and the tyrosyl radical. Therefore, formation of a superoxide is proposed as a possible final reduction step (Scheme 6). The excited state chromophore oxidation is reminiscent of the photoconversion in GFP that results in decarboxylation of Glutamate 222 by the excited singlet state of the neutral green chromophore 13. Photochemical oxidation of molecular oxygen has recently also been discussed in red fluorescent proteins, which are further manifestations of oxidative processes of excited state chromophores in fluorescent proteins ${ }^{34}$.

Considering the various proposals for green-to-red conversion mechanisms for both EosFP and Kaede ${ }^{4,7-8}$, we propose a modified reaction scheme that is initiated by oxidation of the GN ground state. Particularly, we consider the equilibrium between histidine and tyrosyl radicals. It is known from studies on His-Tyr dipeptides that following radical generation the electron transfer is generally favoured to stabilise the tyrosyl radical ${ }^{35}$. This is confirmed by a number of studies that reported midpoint potentials for the individual aminoacids with typical values of $\mathrm{E}(\mathrm{His} \cdot+\mathrm{His}) \mathrm{pH}=1170 \mathrm{mV}, \quad \mathrm{E}(\mathrm{TyrO} / \mathrm{TyrOH}) \mathrm{pH} 7=930 \mathrm{mV}{ }^{36-37}$. Depending on the precise midpoint potentials in the protein a fraction of His-62 could become oxidised to form the His·+ radical following the initial tyrosyl formation. This is in line with the reduced quantum yield of photoconversion relative to the rapid initial generation of tyrosyl in the k1(1) reaction. Taking this as a starting point, a covalent mechanism can be proposed with some modifications relative to that originally proposed by Nienhaus et al. ${ }^{4}$ and similar to pathway intermediates B1, B2, C3 and C4 presented by Li et al. ${ }^{8}$, but replacing the triplet state configuration with radical formation 
(Scheme 8). Furthermore, a carbocation intermediate proposed by Nienhaus et al ${ }^{4}$ is avoided by direct rearrangement as shown in the third structure of Scheme 8. In the final step an electron must be added to form the red chromophore ground state (Scheme 8), which may come from superoxide which has been proposed as a product of chromophore doublet decay (Scheme 6)

\section{Scheme 8}

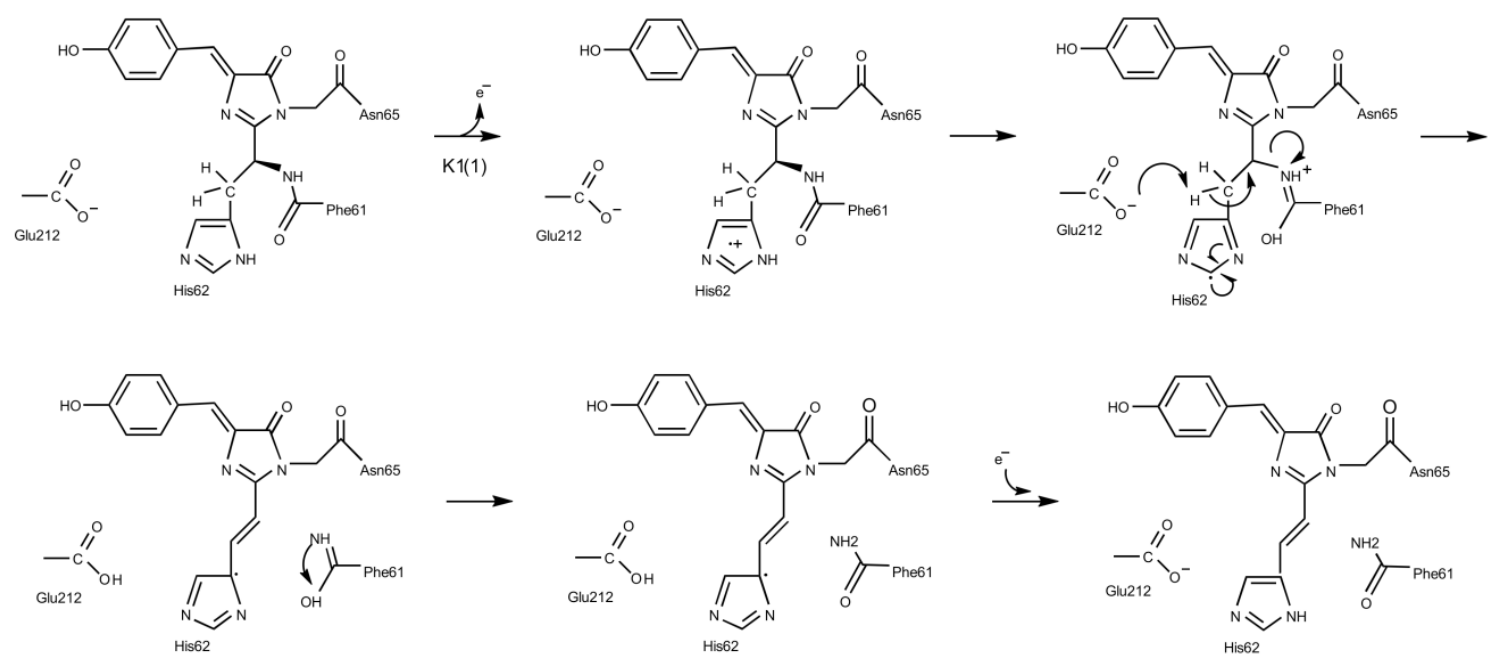

Finally, we consider the possible identity of the tyrosyl radical, from both the experimentally observed Stark shifts in the electronic spectra, as well as from the $\mathrm{pH}$ dependence of its lifetime. At reduced $\mathrm{pH}$ of 5.5, the Stark shift features are most evident from an increase of its lifetime and dominate the absorption differences in the dark Phase 2 (Figure 4), whereas at pH 6.9 its decay is more rapid and Phase 2 spectra primarily show small amplitude GA to RA conversion (Figure 2B). Figure S6 clearly resolves the Stark-shifted features from a partially photoconverted sample of EosFP, showing features on both green and red chromophores. Since the Stark-shift is observed for both reactant (green) and product (red) states, it is concluded that illumination of the red chromophore results in radical formation as well. An alternative mechanism would 
involve inter-chain electron transfer in partially converted tetrameric EosFP complexes. The following provides a structure-based calculation of theoretical Stark shifts, in which emphasis is placed on evaluation of the sign and relative magnitude of the computed shifts, as the main uncertainty relates to the screening of the induced field. The magnitude of the screening is expressed as the effective dielectric constant ${ }^{38}$, which can be in the range of $\sim 1.5-15$ in proteins $39-42$.

$$
\varepsilon_{\text {eff }}=\frac{E_{e}}{E_{\text {net }}}
$$

The stark shift $\Delta \dot{v} \quad$ can be described as a Taylor series, generally truncated to the first or second order ${ }^{43}$.

$$
\Delta \dot{v}=\frac{-1}{h c}\left(\Delta \vec{\mu} \cdot \vec{F}+\frac{1}{2} \vec{F} \cdot \Delta \alpha \cdot \vec{F}+\ldots\right)
$$

Where $\vec{F}$ is the applied field, $\vec{\mu}$ is the difference dipole moment, $h$ is Planck's constant, $\quad c \quad$ is the speed of light, and $\Delta \alpha$ the difference polarizability. In addition, $\vec{F}$ also modifies the transition dipole moment.

Table S2 presents the directional cosines for $\vec{F} \cdot \Delta \vec{\mu}$ for all tyrosine sidechains from Coulombs law assuming a single positive charge

$$
\begin{gathered}
e=i \frac{1}{4 \pi \varepsilon_{0}} \frac{e}{r^{2}} \widehat{r}, \\
\vec{E}_{\zeta}
\end{gathered}
$$


Table S3 presents the chromophore TD-DFT calculations of the difference dipole moment vector and magnitude. Table S4 presents the experimental Stark shifts from Figure S6 and Figure 4, in addition to calculated Stark shifts in wavenumbers. The results show that Tyr 177, which is located closest to the chromophore at $5.3 \AA$ is oriented to provide directional cosines with anionic and neutral green and red chromophores that correspond to the experimental data with regard to the sign of the shifts, i.e. positive for GN and RN and negative for GA and RA (Figure S6, Table S2). Furthermore, the magnitude of the calculated shifts are greatest for Tyr 177, and may well explain the experimental values with application of a $\varepsilon_{\text {rel }}$ value of $\sim 5$, which is also reasonable ${ }^{39-42}$. Two additional arguments can further support Tyr 177 as the location of a transient tyrosyl radical. Firstly, in order for a Stark shift to occur, the oxidation of Tyr $\mathrm{OH}$ should result in a net charge difference. However, the Tyr-OH·+ radical cation is a super-acid, with an estimated pKa value of $-2{ }^{37}$. This is also the basis for proton coupled electron transfer reported for TyrD of Photosystem-II ${ }^{44}$. In PSII, TyrD is hydrogen bonded to a histidine, which accepts the proton following tyrosyl formation. The single charge difference is subsequently also detected by Stark-shift features on nearby pigments. For Tyr 177 of EosFP, a similar situation exists, as it is H-bonded to glutamate 144 with $2.6 \AA$ O-O distance ${ }^{4}$, which could act as a transient proton acceptor (Scheme 7). While no strong signals are seen in the $1710-1780 \mathrm{~cm}^{-1}$ spectral region of phase 2 in pH5.5 conditions (Figure 5), the possibility of a single-well, short hydrogen bond might suppress the intensity. Alternatively, there could be compensating change on other carboxylates, such as that of Glu 212. The second argument considers that the FTIR spectra of $k 1(1)$ and $k 1(2)$ differ significantly in the intensity of the chromophore $v \mathrm{C}=\mathrm{O}(2)$ mode (Figure 5A). A vibrational Stark effect is potentially also present, but mostly the presence of an 
additional field could modify the intensity of the transition directly, as Tyr 177 is indeed located close to the chromophore $\mathrm{C}=\mathrm{O}(2)$ bond.

In conclusion, it is shown that the green-to-red conversion of EosFP involves covalent reactions that are light independent, and triggered by light-induced formation of a radical intermediate. This report collects a significant number of new observations and assignments from molecular spectroscopy, which together provide the details of the very complex molecular reaction mechanisms that result in green-to-red conversion of EosFP. The $\mathrm{pH}$ dependence of the kinetics and spectral differences, the vibrational and electronic spectral assignments in addition to Stark effect and its structural analysis support a tyrosyl radical involvement, likely that of Tyr177. The significant $\mathrm{pH}$ dependence of the spectra and kinetics has been instrumental to unambiguously reveal the Stark shifted features in the electronic spectra which are fundamental to the proposed overall phototransformation mechanism. A structural analysis of the Stark effect that uses the crystal structure coordinates further adds to this evidence. The exceptionally increased spectral width of tyrosyl vibrational modes, proposed to result from rapid transverse dephasing, also highlights the significant magnitude of the electric field associated with the radical species. 

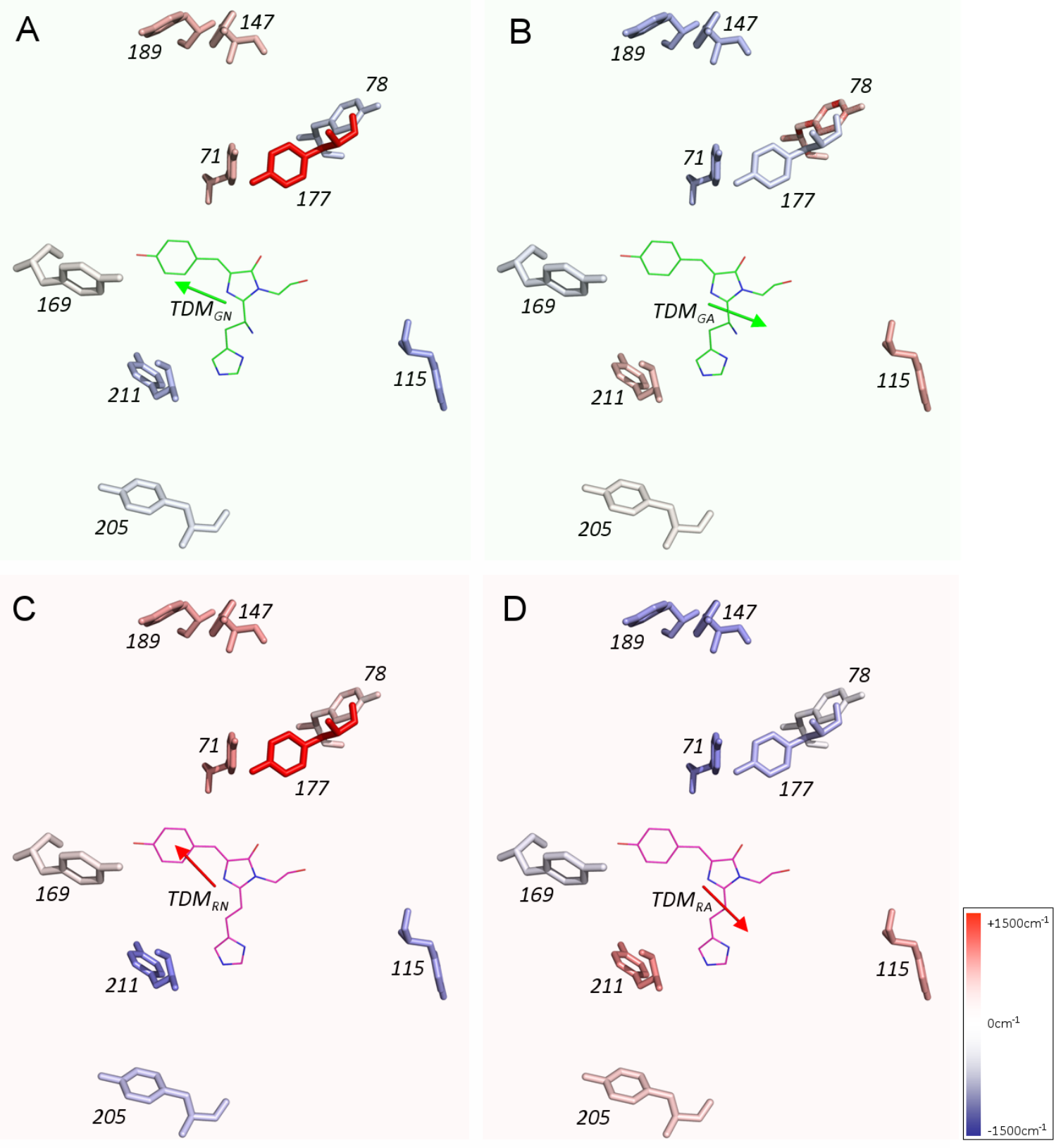

Figure 6. Computed Stark shifts $\Delta v\left(\mathrm{~cm}^{-1}\right)$ for all Tyrosine residues indicated with colouring (numbering from 1ZUX $\mathrm{pdb}^{4}$ ) for the GN (A), GA (B), RN (C) and RA (D) chromophores. Electronic transition dipole moment vectors are calculated at the CAM-B3LYP/6-31+(g,p) level and rotated into the EosFP structure (Tables S2,S3,S4). 


\section{References}

1. Wiedenmann, J.; Ivanchenko, S.; Oswald, F.; Schmitt, F.; Röcker, C.; Salih, A.; Spindler, K.-D.; Nienhaus, G. U., EosFP, a fluorescent marker protein with UV-inducible green-to-red fluorescence conversion. Proceedings of the National Academy of Sciences of the United States of America 2004, 101, 15905-15910.

2. Ando, R.; Hama, H.; Yamamoto-Hino, M.; Mizuno, H.; Miyawaki, A., An optical marker based on the UV-induced green-to-red photoconversion of a fluorescent protein. Proceedings of the National Academy of Sciences 2002, 99 (20), 12651.

3. Mizuno, H.; Mal, T. K.; Tong, K. I.; Ando, R.; Furuta, T.; Ikura, M.; Miyawaki, A., Photo-induced peptide cleavage in the green-to-red conversion of a fluorescent protein. Molecular Cell 2003, 12, 1051-1058.

4. Nienhaus, K.; Nienhaus, G. U.; Wiedenmann, J.; Nar, H., Structural basis for photoinduced protein cleavage and green-to-red conversion of fluorescent protein EosFP. Proceedings of the National Academy of Sciences of the United States of America 2005, 102, 9156-9159. 5. Nienhaus, G. U.; Nienhaus, K.; Hölzle, A.; Ivanchenko, S.; Renzi, F.; Oswald, F.; Wolff, M.; Schmitt, F.; Röcker, C.; Vallone, et al, Photoconvertible fluorescent protein EosFP: biophysical properties and cell biology applications. Photochemistry and photobiology 2006, 82, 351-358.

6. Tsutsui, H.; Shimizu, H.; Mizuno, H.; Nukina, N.; Furuta, T.; Miyawaki, A., The E1 mechanism in photo-induced beta-elimination reactions for green-to-red conversion of fluorescent proteins. Chem Biol 2009, 16, 1140-1147.

7. Lelimousin, M.; Adam, V.; Nienhaus, G. U.; Bourgeois, D.; Field, M. J., Photoconversion of the fluorescent protein EosFP: a hybrid potential simulation study reveals intersystem crossings. Journal of the American Chemical Society 2009, 131, 16814-23.

8. Li, X.; Chung, L. W.; Mizuno, H.; Miyawaki, A.; Morokuma, K., Competitive mechanistic pathways for green-to-red photoconversion in the fluorescent protein kaede: A computational study. Journal of Physical Chemistry B 2010, 114, 16666-16675.

9. Kim, H.; Grunkemeyer, T. J.; Modi, C.; Chen, L.; Fromme, R.; Matz, M. V.; Wachter, R. M., Acid-base catalysis and crystal structures of a least evolved ancestral GFP-like protein undergoing green-to-red photoconversion. Biochemistry 2013, 52, 8048-8059.

10. Kim, H.; Zou, T.; Modi, C.; Dörner, K.; Grunkemeyer, T. J.; Chen, L.; Fromme, R.; Matz, M. V.; Ozkan, S. B.; Wachter, R. M., A hinge migration mechanism unlocks the evolution of green-to-red photoconversion in GFP-like proteins. Structure 2015, 23, 34-43.

11. Thédié, D.; Berardozzi, R.; Adam, V.; Bourgeois, D., Photoswitching of Green mEos2 by Intense $561 \mathrm{~nm}$ Light Perturbs Efficient Green-to-Red Photoconversion in Localization Microscopy. The Journal of Physical Chemistry Letters 2017, 8, 4424-4430. 
12. Makarov, N. S.; Cirloganu, C.; Perry, J. W.; Lukyanov, K. A.; Solntsev, K. M., Steadystate and time-resolved spectroscopic studies of green-to-red photoconversion of fluorescent protein Dendra2. Journal of Photochemistry and Photobiology A: Chemistry 2014, 280, 5-13. 13. van Thor, J. J.; Gensch, T.; Hellingwerf, K. J.; Johnson, L. N., Phototransformation of green fluorescent protein with UV and visible light leads to decarboxylation of glutamate 222 . Nature structural biology 2002, 9, 37-41.

14. Klementieva, N. V.; Lukyanov, K. A.; Markina, N. M.; Lukyanov, S. A.; Zagaynova, E. V.; Mishin, A. S., Green-to-red primed conversion of Dendra2 using blue and red lasers. Chemical Communications 2016, 52, 13144-13146.

15. Dempsey, W. P.; Georgieva, L.; Helbling, P. M.; Sonay, A. Y.; Truong, T. V.; Haffner, M.; Pantazis, P., In vivo single-cell labeling by confined primed conversion. Nature Methods 2015, 12, 645-648.

16. van Wilderen, L.; Lincoln, C. N.; van Thor, J. J., Modelling Multi-Pulse Population Dynamics from Ultrafast Spectroscopy. Plos One 2011, 6 (3).

17. Dorlhiac, G. F.; Fare, C.; van Thor, J. J., PyLDM - An open source package for lifetime density analysis of time-resolved spectroscopic data. Plos Computational Biology 2017, 13 (5).

18. Van Thor, J. J.; Pierik, A. J.; Nugteren-Roodzant, I.; Xie, A.; Hellingwerf, K. J., Characterization of the photoconversion of green fluorescent protein with FTIR spectroscopy. Biochemistry 1998, 37, 16915-16921.

19. Van Thor, J. J.; Georgiev, G. Y.; Towrie, M.; Sage, J. T., Ultrafast and low barrier motions in the photoreactions of the green fluorescent protein. Journal of Biological Chemistry 2005, 280, 33652-33659.

20. van Thor, J. J.; Zanetti, G.; Ronayne, K. L.; Towrie, M., Structural events in the photocycle of green fluorescent protein. The journal of physical chemistry. B 2005, 109, 16099108.

21. van Thor, J. J.; Ronayne, K. L.; Towrie, M.; Sage, J. T., Balance between ultrafast parallel reactions in the green fluorescent protein has a structural origin. Biophysical journal 2008, 95, 1902-12.

22. Esposito, a. P.; Schellenberg, P.; Parson, W. W.; Reid, P. J., Vibrational spectroscopy and mode assignments for an analog of the green fluorescent protein chromophore. Journal of Molecular Structure 2001, 569, 25-41.

23. He, X.; Bell, A. F.; Tonge, P. J., Isotopic labeling and normal-mode analysis of a model green fluorescent protein chromophore. Journal of Physical Chemistry B 2002, 106, 6056-6066. 24. Warren, M. M.; Kaucikas, M.; Fitzpatrick, A.; Champion, P.; Sage, J. T.; van Thor, J. J., Ground-state proton transfer in the photoswitching reactions of the fluorescent protein Dronpa. Nature communications 2013, 4, 1461-1469.

25. Barth, A.; Zscherp, C., What vibrations tell about proteins. Quarterly Reviews of Biophysics 2002, 35, S0033583502003815.

26. Giovani, B.; Byrdin, M.; Ahmad, M.; Brettel, K., Light-induced electron transfer in a cryptochrome blue-light photoreceptor. Nature Structural \& Molecular Biology 2003, 10, 489490.

27. Aubert, C.; Mathis, P.; Eker, A. P. M.; Brettel, K., Intraprotein electron transfer between tyrosine and tryptophan in DNA photolyase from Anacystis nidulans. Proceedings of the

National Academy of Sciences 1999, 96, 5423-5427. 
28. Feitelson, J.; Hayon, E., Electron ejection and electron capture by phenolic compounds. The Journal of Physical Chemistry 1973, 77, 10-15.

29. Oldemeyer, S.; Franz, S.; Wenzel, S.; Essen, L.-O.; Mittag, M.; Kottke, T., Essential Role of an Unusually Long-lived Tyrosyl Radical in the Response to Red Light of the Animal-like Cryptochrome aCRY. Journal of Biological Chemistry 2016, 291, 14062-14071.

30. Berthomieu, C.; Boussac, A., FTIR and EPR study of radicals of aromatic amino acids 4methylimidazole and phenol generated by UV irradiation. Biospectroscopy 1995, 1, 187-206.

31. Barry, B. A., Reaction dynamics and proton coupled electron transfer: Studies of tyrosinebased charge transfer in natural and biomimetic systems. Biochimica et Biophysica Acta (BBA) Bioenergetics 2015, 1847, 46-54.

32. Premont-Schwarz, M.; Xiao, D. Q.; Batista, V. S.; Nibbering, E. T. J., The O-H Stretching Mode of a Prototypical Photoacid as a Local Dielectric Probe. Journal of Physical Chemistry A 2011, 115 (38), 10511-10516.

33. Byrdin, M.; Duan, C.; Bourgeois, D.; Brettel, K., A Long-Lived Triplet State Is the Entrance Gateway to Oxidative Photochemistry in Green Fluorescent Proteins. Journal of the American Chemical Society 2018, 140, 2897-2905.

34. Vegh, R. B.; Bravaya, K. B.; Bloch, D. A.; Bommarius, A. S.; Tolbert, L. M.; Verkhovsky, M.; Krylov, A. I.; Solntsev, K. M., Chromophore photoreduction in red fluorescent proteins is responsible for bleaching and phototoxicity. Journal of Physical Chemistry B 2014, 118, 45274534.

35. Morozova, O. B.; Yurkovskaya, A. V., Intramolecular electron transfer in the photooxidized peptides tyrosine-histidine and histidine-tyrosine: A time-resolved CIDNP study. Angewandte Chemie - International Edition 2010, 49, 7996-7999.

36. Navaratnam, S.; Parsons, B. J., Reduction potential of histidine free radicals: a pulse radiolysis study. Journal of the Chemical Society, Faraday Transactions 1998, 94, 2577-2581. 37. Tommos, C.; Skalicky, J. J.; Pilloud, D. L.; Wand, A. J.; Dutton, P. L., De Novo Proteins as Models of Radical Enzymes $†$. Biochemistry 1999, 38, 9495-9507.

38. Lockhart, D.; Kim, P., Internal stark effect measurement of the electric field at the amino terminus of an alpha helix. Science 1992, 257, 947-951.

39. Boxer, S. G., Stark Realities †. The Journal of Physical Chemistry B 2009, 113, 29722983.

40. Bublitz, G.; King, B. A.; Boxer, S. G., Electronic Structure of the Chromophore in Green Fluorescent Protein (GFP). Journal of the American Chemical Society 1998, 120, 9370-9371.

41. Dashdorj, N.; Xu, W.; Martinsson, P.; Chitnis, P. R.; Savikhin, S., Electrochromic Shift of Chlorophyll Absorption in Photosystem I from Synechocystis sp. PCC 6803: A Probe of Optical and Dielectric Properties around the Secondary Electron Acceptor. Biophysical Journal 2004, 86, 3121-3130.

42. Steffen, M. A.; Lao, K.; Boxer, S. G., Dielectric Asymmetry in the Photosynthetic Reaction Center. Science 1994, 264, 810-816.

43. Silverman, L. N.; Spry, D. B.; Boxer, S. G.; Fayer, M. D., Charge Transfer in Photoacids Observed by Stark Spectroscopy. The Journal of Physical Chemistry A 2008, 112, 10244-10249. 44. Faller, P.; Goussias, C.; Rutherford, a. W.; Un, S., Resolving intermediates in biological proton-coupled electron transfer: A tyrosyl radical prior to proton movement. Proceedings of the National Academy of Sciences 2003, 100, 8732-8735. 


\section{Supplementary Information}

Harmonic Frequency calculations for the GA, GN, RA and RN chromophores and the secondary Amide product; Structure based Stark shift calculation for all Tyrosine residues in EosFP; TDDFT calculations GN,GA,RN and RA chromophores.; Experimental Stark shift parameters for the GA,RN,RA, RN-S2 and RA-S2 chromophores; Time resolved UV-VIS difference spectra of EosFP in ${ }^{2} \mathrm{H}_{2} \mathrm{O}$ at p ${ }^{2} \mathrm{H} 6.9$; Thermal phase 2 components for time resolved FTIR light-minusdark difference spectra of EosFP at $\mathrm{p}^{2} \mathrm{H}$ 6.9; Repeat measurement example of light induced "Phase 1" time resolved UV-VIS difference spectra of EosFP at $\mathrm{p}^{1} \mathrm{H}$ 5.1; Time resolved FTIR measurements in ${ }^{1} \mathrm{H}_{2} \mathrm{O}$ at $\mathrm{p}^{1} \mathrm{H} 5.1$ with fitting of three rate constants ; Time-resolved UV-VIS measurements with illumination (Phase 3), following partial conversion (Phase 1) and dark conversion (Phase 2), at $\mathrm{p}^{2} \mathrm{H} 5.1$; Global fitting procedure for time resolved FTIR measurements for the ${ }^{2} \mathrm{H}_{2} \mathrm{O}$ conditions at $\mathrm{p}^{2} \mathrm{H}$ 6.9. ; Global fitting procedure for time resolved UV-VIS measurements for ${ }^{1} \mathrm{H}_{2} \mathrm{O}$ conditions and $\mathrm{p}^{1} \mathrm{H} 6.9$

\section{Acknowledgements}

We thank Dr. Erik Nibbering for helpful discussion. JJvT acknowledges support from the Biotechnology and Biological Sciences Research Council (BBSRC) (No. BB/P00752X/1). Clyde Fare was supported in part by EPSRC (EP/I003304/1). PRR was funded by the UK Biotechnology and Biological Sciences Research Council (award BB/K001094/1).

Dedication: To the memory of Letong Yuan, who had only just started her scientific journey. Rest in peace, friend. 
Table of contents graphic
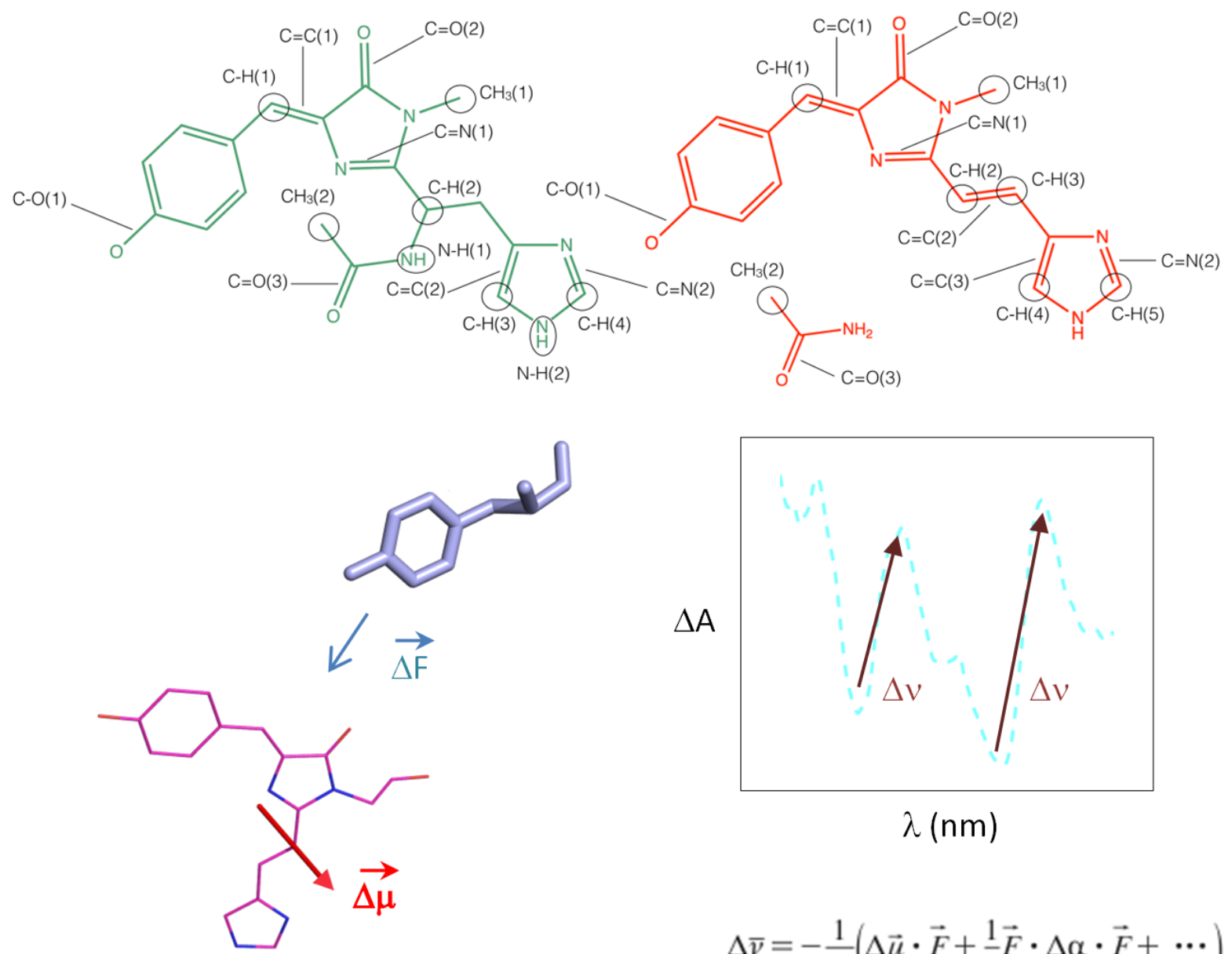

$$
\Delta \bar{v}=-\frac{1}{h c}\left(\Delta \vec{\mu} \cdot \vec{F}+\frac{1}{2} \vec{F} \cdot \Delta \alpha \cdot \vec{F}+\cdots\right)
$$

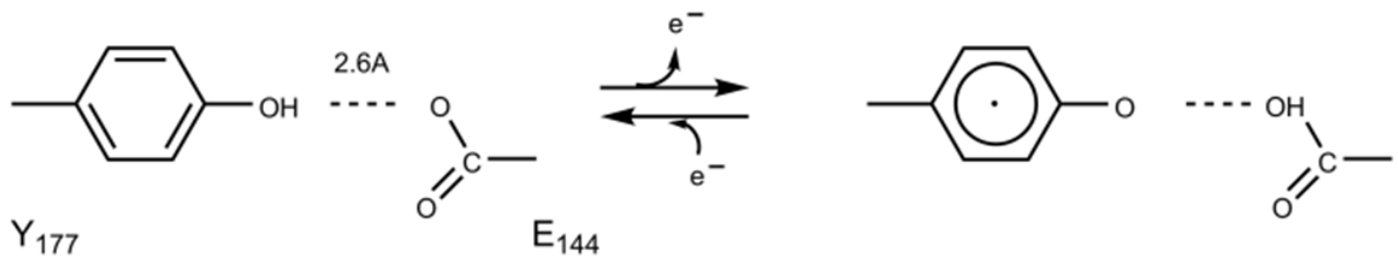

